\title{
Virtual Electric Dipole Field Applied to Autonomous Formation Flight Control of Unmanned Aerial Vehicles
}

\author{
Leszek Ambroziak ${ }^{1, *(1)}$ and Maciej Ciężkowski ${ }^{2}$ \\ 1 Robotics and Mechatronics Department, Faculty of Mechanical Engineering, \\ Bialystok University of Technology, Wiejska St. 45C, 15-351 Bialystok, Poland \\ 2 Automatic Control and Robotics Department, Faculty of Electrical Engineering, \\ Bialystok University of Technology, Wiejska St. 45E, 15-351 Bialystok, Poland; m.ciezkowski@pb.edu.pl \\ * Correspondence: 1.ambroziak@pb.edu.pl; Tel.: +48-571-443-041
}

check for updates

Citation: Ambroziak, L.; Ciężkowski, M. Virtual Electric Dipole Field Applied to Autonomous Formation Flight Control of Unmanned Aerial Vehicles. Sensors 2021, 21, 4540. https://doi.org/10.3390/s21134540

Academic Editors: Enrico Natalizio and Andrey V. Savkin

Received: 7 May 2021

Accepted: 28 June 2021

Published: 1 July 2021

Publisher's Note: MDPI stays neutral with regard to jurisdictional claims in published maps and institutional affiliations.

Copyright: (c) 2021 by the authors. Licensee MDPI, Basel, Switzerland. This article is an open access article distributed under the terms and conditions of the Creative Commons Attribution (CC BY) license (https:// creativecommons.org/licenses/by/ $4.0 /)$.

\begin{abstract}
The following paper presents a method for the use of a virtual electric dipole potential field to control a leader-follower formation of autonomous Unmanned Aerial Vehicles (UAVs). The proposed control algorithm uses a virtual electric dipole potential field to determine the desired heading for a UAV follower. This method's greatest advantage is the ability to rapidly change the potential field function depending on the position of the independent leader. Another advantage is that it ensures formation flight safety regardless of the positions of the initial leader or follower. Moreover, it is also possible to generate additional potential fields which guarantee obstacle and vehicle collision avoidance. The considered control system can easily be adapted to vehicles with different dynamics without the need to retune heading control channel gains and parameters. The paper closely describes and presents in detail the synthesis of the control algorithm based on vector fields obtained using scalar virtual electric dipole potential fields. The proposed control system was tested and its operation was verified through simulations. Generated potential fields as well as leader-follower flight parameters have been presented and thoroughly discussed within the paper. The obtained research results validate the effectiveness of this formation flight control method as well as prove that the described algorithm improves flight formation organization and helps ensure collision-free conditions.
\end{abstract}

Keywords: formation flight control; guidance; unmanned aerial vehicles; potential field; virtual electric dipole

\section{Introduction}

Over the past decade, Unmanned Aerial Systems (UAS) have advanced greatly, mostly due to the dynamic progress in robotics, control engineering, telecommunication, and material sciences [1-3]. In general, the R\&D community dealing with UAS has been facing several new issues, such as those connected with increasing autonomy levels [4-7], communication and data exchange systems [8-10], precise localization systems [11,12], propulsion and power systems [13,14], launchers and take off system [15-17], mannedunmanned teaming [18], interoperability [19-21], advanced control laws synthesis [22-24] and many others. However, within the last several years, a lot of attention has been focused on cooperative control, especially formation flight [25-28]. An effective and robust formation flight can strongly improve the operational potential of UAS [29,30]. Multiple UAVs that fly in formation and have the ability to work together can hold a prominent role in applications like military operations, map building, transport of heavy or bulky loads, search and rescue missions, aerial refueling, drag reduction, and energy savings or long-distance data retransmission. Efficient formation flying requires the development and testing of appropriate control laws. This is especially true in respect to small UAVs having low payload capacities which severely limit onboard sensor suites or flight computers and communication systems that they can carry. For this reason, control laws should be simple 
and provide reliable operation which, in turn, makes their design challenging. The problem of formation flight control has been well documented and widely considered in literature.

Formation flight control systems can be classified according to a number of criteria with the most important being the type of information they use and the way this information is exchanged. Examples include (i) systems based on a radio data exchange (most often concerning positions and velocities of objects within a group), (ii) those relying on video information that is obtained from cameras and computer vision systems [31,32], and (iii) systems based on specialized sensors - such as seekers [33]. Another manner of classifying formation control systems is through the structure of their control system and dependencies related to communication and data exchange. Three of the most commonly used structures are (i) leader-follower [34,35], (ii) virtual structure [36] and (iii) behavioral approach [37]. Flight formation control methods can also be categorized on the basis of the control system's organizational arrangement (according to the place where decision making and control occurs), with examples including (i) centralized, (ii) decentralized, and (iii) hybrid. We can also divide the methods with regard to the type of control object and its kinematic properties. Methods can also be classified with respect to their control object, such as (i) nonholonomic [38,39] and (ii) holonomic, and its kinematic properties. There are also formations of homogeneous and heterogeneous objects [40].

In considering solely the technique used for formation flight control, it is possible to mention methods utilizing proportional-integral controllers [41-43], nonlinear [44,45] or with switching controllers [46]. Other types of controllers like optimal [47,48], adaptive [49,50], predictive [51] or robust [52] have also been analyzed and evaluated. In [53] and [54], for example, trajectory optimization methods for multiple agents of formation flight were presented and carefully discussed. An efficient and optimal path smoothing technique for UAV formation path planning that accounts for moving obstacles is proposed in [55] and for guiding a UAV to a desired position. However, artificial potential field derivation, their handling, and usage are carried out in various ways. Works [56-59], for example, utilized bifurcating potential fields to determine the desired airspeed and heading of a fixed-wing UAV and focused on keeping the aircraft on the desired trajectory defined as a constant radius circle or as a straight line. The authors of these works consider a decentralized control methodology without a leader. The [60], on the other hand, presents a virtual leader approach combined with an extended local potential field. This method was applied only with respect to small unmanned helicopters and is only suitable for holonomic mobile objects, greatly limiting its uses. The most frequently used methods of formation control represent the position or displacement-based approaches where objects measure their position or relative position within a global coordinate system. [61] proposes a formation control system that uses information concerning the line of sight angles but only with respect to nearby agents. Furthermore, it is important that the proposed algorithm does not require a communication link for data exchange between vehicles. A similar idea for controlling the formation of flying robots without relative position determination of each vehicle was proposed in [62] where the detective deviated pursuit rule regulates the distances between vehicles.

The present work also addresses the problem of UAV formation flight control. The algorithm proposed within the work uses a potential field to determine the desired heading for the follower UAV. A great advantage of this method is the ability to rapidly change this potential field function depending on the position of an independent leader. What is more, the potential field is generated in a manner that provides collision avoidance during formation flight. The system is decentralized and based on a leader-follower configuration and could be easily adapted to vehicles with different dynamics without having to retune heading control channel gains and parameters. One of the paper's main goals was to conduct simulation tests of the proposed formation flight control system. The leader-follower simulation onboard control system was designed in a manner that corresponds to commercial autopilots and was carefully described in the paper. The synthesis of the potential field control algorithm is also closely described and presented in 
detail. The proposed control system was thoroughly tested and verified during simulations. Longitudinal and lateral positions of the UAVs (leader and follower) obtained during the tests were recorded and then presented on plots. Furthermore, waveforms of position errors were introduced to show control system quality. Generated vector fields, as well as the logged leader and follower flight parameters, were subjected to careful consideration. The Obtained results validate the effectiveness of the vector field-based formation flight control method and the developed control algorithm improves formation flight organization, provides a simple and computationally efficient method for controlling, and helps to ensure collision-free flight of multiple UAVs.

The remainder of the paper is organized in the following manner: Section 2 includes a thorough description of the research object, its mathematical model, and simulation system while the main definitions of the virtual electric dipole field and formation flight problem are formulated in Section 3. Section 4 presents the validation of the proposed navigation strategy conducted using computer simulations and illustrative examples. Comprehensive conclusions are presented in Section 5 .

\section{Research Object}

\subsection{The Bullit 60}

The study utilized the Bullit 60, a micro air vehicle (MAV) [63] (Figure 1), which is a fixed-wing aircraft of the flying wing configuration. The control surfaces in a flying wing are commonly called elevons. The angular deflections of the right and left elevons are labeled as $\delta_{e_{r}}$ and $\delta_{e_{l}}$, respectively. Using the following formulas, we can convert elevon singnals into a standard aileron-elevator $\left(\delta_{a}\right.$ and $\left.\delta_{e}\right)$ signals [64-66]:

$$
\begin{aligned}
& \delta_{e}=\delta_{e_{r}}+\delta_{e_{l}} \\
& \delta_{a}=-\delta_{e_{r}}+\delta_{e_{l}}
\end{aligned} .
$$

Therefore, the mathematical model of the MAV presented in the next paragraph will be expressed in terms of standard aileron-elevator notation. The Bullit 60 is made of balsa wood covered with plastic skin and is powered by a front-mounted electric motor. Its propulsion system is composed of a two-blade, $14^{\prime \prime} \times 8^{\prime \prime}$ propeller that has an area $\left(S_{p}\right)$ of $0.0031 \mathrm{~m}^{2}$. The MAV's wing is configured as a single-delta and has a symmetrical, bi-convex BELL 540 (modification of NACA0012) profile. The wing span $(b)$ of the Bullit 60 is $1.095 \mathrm{~m}$, whereas the wing area $(S)$ is $49.7 \mathrm{dm}^{2}$. The other important aerodynamic wing parameters are the mean chord $(c)$ and the tip chord that are $0.660 \mathrm{~m}$ and 0.170 respectively. The total length $(l)$ of the UAV is $0.770 \mathrm{~m}$ and its total ready-to-fly mass $(m)$ is $1.8 \mathrm{~kg}$. The vehicle's maximum airspeed $\left(V_{\max }\right)$ is $34 \mathrm{~m} / \mathrm{s}$ and and its minimum velocity $\left(V_{\min }\right)$ is $11 \mathrm{~m} / \mathrm{s}$.

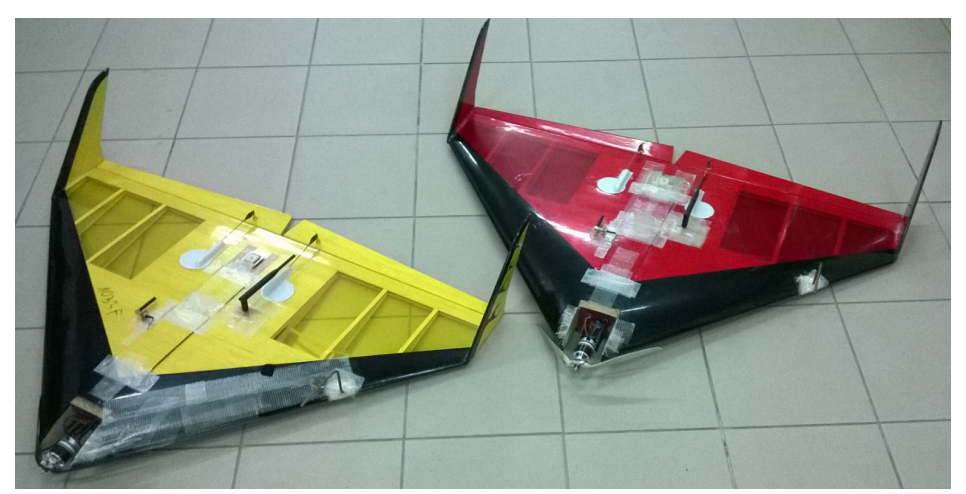

Figure 1. Bullit $60 \mathrm{MAV}$ used in the studies. 


\subsection{Mathematical Model}

To characterize the spatial motion of a UAV it is crucial to consider the action of forces and moments on the vehicle. To complete the mathematical model, it is also important to account for kinematic relations.

The considered $U A V$ is symmetrical within the $x-z$ plane. Consequently, the inertia matrix (please refer to Table 1) can be expressed as:

$$
\hat{I}=\left(\begin{array}{ccc}
I_{x} & 0 & I_{x z} \\
0 & I_{y} & 0 \\
-I_{x z} & 0 & I_{z}
\end{array}\right)
$$

Table 1. Bullit 60 moments and products of inertia.

\begin{tabular}{cc}
\hline Moment of Inertia & Value \\
\hline$I_{x}$ & $0.091108\left[\mathrm{kgm}^{2}\right]$ \\
$I_{y}$ & $0.076144\left[\mathrm{kgm}^{2}\right]$ \\
$I_{z}$ & $0.165955\left[\mathrm{kgm}^{2}\right]$ \\
$I_{x z}$ & $0.0011547\left[\mathrm{kgm}^{2}\right]$ \\
\hline
\end{tabular}

The six-degree-of-freedom, 12-state model with externally applied forces and moments due to gravity, aerodynamics, and propulsion system can be presented through Equations (2)-(5). Aerodynamic parameters (lateral and longitudinal) of the Bullit 60 were calculated using Advanced Aircraft Analysis (AAA) computer software developed by the DAR Corp. [67] and the Tornado VLM software [68] and were compared with wind tunnel experiments [69]. The Bullit equations of motion that have been applied in the present study are as follows:

$$
\begin{gathered}
{\left[\begin{array}{c}
\dot{x} \\
\dot{y} \\
\dot{z}
\end{array}\right]=Q_{1}\left[\begin{array}{c}
u \\
v \\
w
\end{array}\right],} \\
{\left[\begin{array}{c}
\dot{u} \\
\dot{v} \\
\dot{w}
\end{array}\right]=\left[\begin{array}{l}
r v-q w \\
p w-r u \\
q u-p v
\end{array}\right]+Q_{2},} \\
{\left[\begin{array}{c}
\dot{\phi} \\
\dot{\theta} \\
\dot{\psi}
\end{array}\right]=Q_{3}\left[\begin{array}{l}
p \\
q \\
r
\end{array}\right],} \\
{\left[\begin{array}{c}
\dot{p} \\
\dot{q} \\
\dot{r}
\end{array}\right]=Q_{4}+Q_{5},}
\end{gathered}
$$

where:

$$
\begin{gathered}
Q_{1}=\left[\begin{array}{ccc}
\cos \theta \cos \psi & \sin \phi \sin \theta \cos \psi-\cos \phi \sin \psi & \cos \phi \sin \theta \cos \psi+\sin \phi \sin \psi \\
\cos \theta \sin \psi & \sin \phi \sin \theta \sin \psi+\cos \phi \cos \psi & \cos \phi \sin \theta \sin \psi-\sin \phi \cos \psi \\
\sin \theta & -\sin \phi \cos \theta & -\cos \phi \cos \theta
\end{array}\right], \\
Q_{2}=\left[\begin{array}{c}
-g \sin \theta+\frac{\rho V_{*}^{2}}{2 m} S\left[C_{X}(\alpha)+C_{X_{q}}(\alpha) \frac{c q}{2 V_{*}}+C_{X_{\delta_{e}}}(\alpha)\right]+\frac{\rho S_{p} C_{p}}{2 m}\left[\left(k_{M} \delta_{t}\right)^{2}-V_{*}^{2}\right] \\
g \sin \phi \cos \theta+\frac{\rho V_{*}^{2}}{2 m} S\left[C_{Y_{0}}+C_{Y_{\beta}}+C_{Y_{p}} \frac{b p}{2 V_{*}}+C_{Y_{r}} \frac{b r}{2 V_{*}}+C_{Y_{\delta_{a}}} \delta_{a}\right] \\
g \cos \phi \cos \theta+\frac{\rho V_{*}^{2}}{2 m} S\left[C_{Z}(\alpha)+C_{Z_{q}}(\alpha)+C_{Y_{p}} \frac{c q}{2 V_{*}}+C_{Z_{\delta_{e}}}(\alpha) \delta_{e}\right]
\end{array}\right],
\end{gathered}
$$




$$
\begin{aligned}
& Q_{3}=\left[\begin{array}{ccc}
1 & \sin \phi \tan \theta & \cos \phi \tan \theta \\
0 & \cos \phi & -\sin \phi \\
0 & \frac{\sin \phi}{\cos \theta} & \frac{\cos \phi}{\cos \theta}
\end{array}\right], \\
& Q_{4}=\left[\begin{array}{l}
\frac{I_{x z}\left(I_{x}-I_{y}+I_{z}\right)}{I_{x} I_{z}-I_{x z}^{2}} p q-\frac{I_{z}\left(I_{z}-I_{y}\right)+I_{x z}^{2}}{I_{x} I_{z}-I_{x z}^{2}} q r \\
\frac{I_{z}-I_{x}}{I_{y}} p r-I_{x} I_{y} p r-\frac{I_{x z}}{I_{y}}\left(p^{2}-r^{2}\right) \\
\frac{\left(I_{x}-I_{y}\right) I_{x}+I_{x z}^{2}}{I_{x} I_{z}-I_{x z}^{2}} p q-\frac{I_{x z}\left(I_{x}-I_{y}+I_{z}\right)}{I_{x} I_{z}-I_{x z}^{2}} q r
\end{array}\right], \\
& Q_{5}=\left[\begin{array}{c}
\frac{\rho V_{a}^{2} b S}{2} C_{l_{0}}+C_{l_{\beta}} \beta+\left[C_{l_{p}} \frac{b}{2 V_{*}} p+C_{l_{r}} \frac{b}{2 V_{*}} r+C_{l_{\delta_{a}}} \delta_{a}\right]+\ldots \\
\frac{\rho V_{a}^{2} S c}{2}\left[C_{m_{0}}+C_{m_{\alpha}} \alpha+\ldots\right. \\
\frac{\rho V_{*}^{2} b S}{2}\left[C_{l_{0}}+C_{l_{\beta}} \beta+C_{l_{p}} \frac{b}{2 V_{*}} p+C_{l_{r}} \frac{b}{2 V_{*}} r+C_{l_{\delta_{a}}} \delta_{a}\right]+\ldots
\end{array}\right. \\
& \ldots+\frac{\rho V_{a}^{2} b S}{2}\left[C_{n_{0}} C_{n_{\beta}} \beta+C_{n_{p}} \frac{b}{2 V_{*}} p+C_{n_{r}} \frac{b}{2 V_{*}} r+C_{n_{\delta_{a}}} \delta_{a}\right] \\
& \left.\ldots+C_{m_{q}} \frac{c}{2 V_{*}} q+C_{m_{\delta_{e}}} \delta_{e}\right] \\
& \left.\ldots+\frac{\rho V_{*}^{2} b S}{2}\left[C_{n_{0}}+C_{n_{\beta}} \beta+C_{n_{p}} \frac{b}{2 V_{*}} p+C_{n_{r}} \frac{b}{2 V_{*}} r+C_{n_{\delta_{a}}} \delta_{a}\right]\right] \\
& C_{X_{\alpha}}=-C_{D_{\alpha}} \cos \alpha+C_{L_{\alpha}} \sin \alpha, \\
& C_{X_{q}}=-C_{D_{q}} \cos \alpha+C_{L_{q}} \sin \alpha \text {, } \\
& C_{X_{\delta_{e}}}=-C_{D_{\delta_{e}}} \cos \alpha+C_{L_{\delta_{e}}} \sin \alpha \text {, } \\
& C_{Z_{\alpha}}=-C_{D_{\alpha}} \sin \alpha-C_{L_{\alpha}} \cos \alpha \text {, } \\
& C_{Z_{q}}=-C_{D_{q}} \sin \alpha-C_{L_{q}} \cos \alpha \text {, } \\
& C_{Z_{\delta_{e}}}=-C_{D_{\delta_{e}}} \sin \alpha-C_{L_{\delta_{e}}} \cos \alpha \\
& C_{X_{\alpha}}, C_{X_{q}}, C_{X_{\delta^{\prime}}}, C_{Z_{\alpha}}, C_{Z_{q}}, C_{Z_{\delta_{e}}} \text {-nonlinear functions of angle of attack; } \\
& x \text {-inertial North UAV position in the } \boldsymbol{O}_{g} \boldsymbol{X}_{g} \boldsymbol{Y}_{g} \boldsymbol{Z}_{g} \text { (Figure 2); } \\
& y \text {-inertial East UAV position in the } \boldsymbol{O}_{g} \boldsymbol{X}_{g} \boldsymbol{Y}_{g} \boldsymbol{Z}_{g} \text { (Figure 2); } \\
& z \text {-inertial Down position in } \boldsymbol{O}_{g} \boldsymbol{X}_{g} \boldsymbol{Y}_{g} \boldsymbol{Z}_{g} \text { (Figure 2); } \\
& \phi, \theta, \psi \text {-roll angle, pitch angle, yaw angle respectively; } \\
& u, v, w \text {-body frame velocities measured in } \boldsymbol{O X}_{b} \boldsymbol{Y}_{b} \mathbf{Z}_{b} \text { (Figure 2); } \\
& p, q, r \text {-angular rates measured in } \boldsymbol{O X}_{b} \boldsymbol{Y}_{b} \boldsymbol{Z}_{b} \text { (roll rate, pitch rate, yaw rate respectively); } \\
& \boldsymbol{O X}_{v} \boldsymbol{Y}_{v} \mathbf{Z}_{v}-\mathrm{MAV} \text { vehicle frame with origin in the MAV center of mass, axes are aligned } \\
& \text { with } \boldsymbol{O}_{g} \boldsymbol{X}_{g} \boldsymbol{Y}_{g} \boldsymbol{Z}_{g} \text { axis; } \\
& C_{*} \text { - aerodynamic coefficients (values in a Tables } 2 \text { and } 3 \text { ); } \\
& \delta_{a}, \delta_{e}, \delta_{t} \text {-aileron, elevator, throttle commands; } \\
& V_{*} \text {-airspeed; } \\
& \beta \text {-sideslip angle. }
\end{aligned}
$$




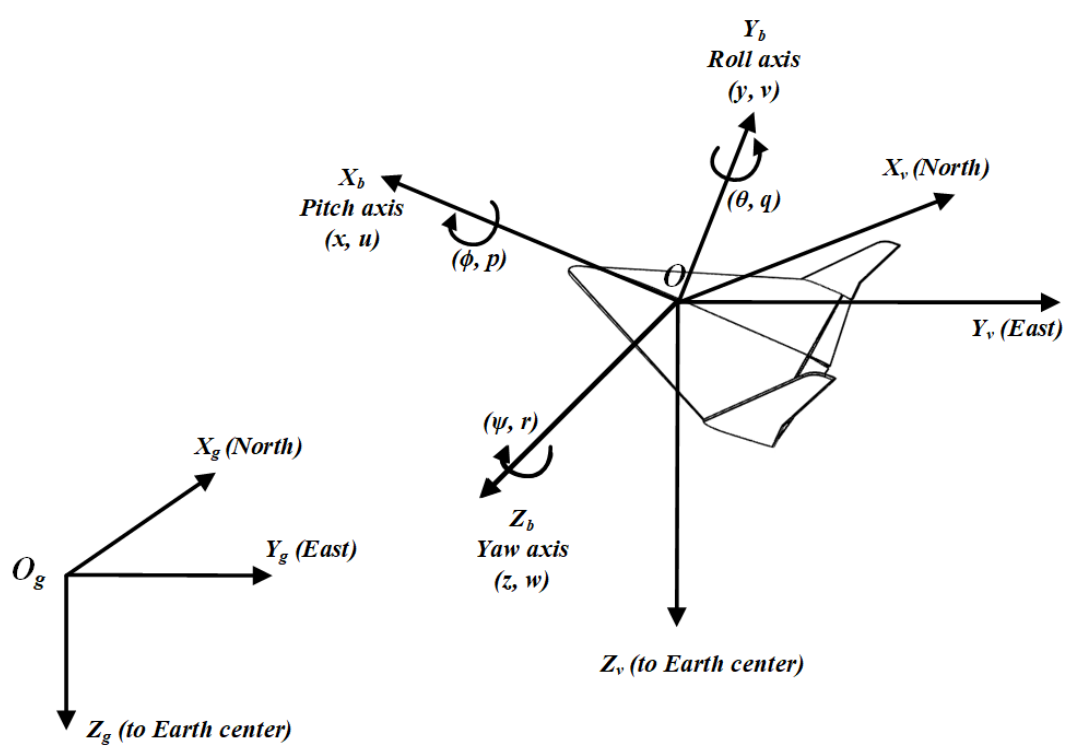

Figure 2. Definitions of coordinate frames.

Table 2. The Bullit logitudinal aerodynamic coefficients.

\begin{tabular}{cccccc}
\hline$C_{L_{0}}$ & $C_{D_{0}}$ & $C_{m_{0}}$ & $C_{L_{\alpha}}$ & $C_{D_{\alpha}}$ & $C_{m_{\alpha}}$ \\
\hline 0.14635 & 0.00293 & -0.030586 & 2.8074 & 0.08759 & -0.59632 \\
\hline$C_{L_{q}}$ & $C_{D_{q}}$ & $C_{m_{q}}$ & $C_{L_{\delta_{e}}}$ & $C_{D_{\delta_{e}}}$ & $C_{m_{\delta_{e}}}$ \\
\hline 4.0992 & 0.12967 & -1.6137 & 1.05 & 0.0338 & -0.61558 \\
\hline
\end{tabular}

Table 3. The Bullit lateral aerodynamic coefficients.

\begin{tabular}{ccccc}
\hline$C_{Y_{0}}$ & $C_{l_{0}}$ & $C_{n_{0}}$ & $C_{\chi_{\beta}}$ & $C_{l_{\beta}}$ \\
\hline $\begin{array}{c}-6.6478 \\
10^{-19}\end{array}$ & $4.3476 \times 10^{-18}$ & $6.855 \times 10^{-19}$ & -0.022517 & -0.043166 \\
\hline$C_{n_{\beta}}$ & $C_{Y_{p}}$ & $C_{l_{p}}$ & $C_{n_{p}}$ & $C_{Y_{r}}$ \\
\hline-0.0608 & 0.1144 & -0.13669 & 0.0293 & -0.14037 \\
\hline$C_{l_{r}}$ & $C_{n_{r}}$ & $C_{\gamma_{\delta_{a}}}$ & $C_{l_{\delta_{a}}}$ & $C_{\boldsymbol{n}_{\delta_{a}}}$ \\
\hline 0.026176 & -0.038383 & $-2.8334 \times$ & $1.8034 \times 10^{-1}$ & $-9.3649 \times$ \\
\hline
\end{tabular}

\subsection{MAV Simulation System}

The 12 nonlinear, coupled, first-order, ordinary differential Equations (2)-(5) represent the mathematical model of the MAV. Based on these equations, a simulation model was constructed in Matlab/Simulink software using specialized toolboxes like Control System [70], Flight Dynamics and Control [71], and Aerospace [72]. Presented Equations (2)-(5) create the MAV's kinematics and dynamics block (Figure 3). Additionally, an autopilot model whose primary goal is to control the MAV's inertial position and attitude was also developed. Apart from stabilization and navigation control loops, the developed simulation model of the Bullit 60 includes formation flight control loops, path following and path planning functions as well as a trajectory generator block (Figure 3). Path-following functions generate commands to low-level control loops (stabilization and navigation control loops). The path planning block produces a sequence of straight-line paths that maneuver the MAV. The block labeled as the trajectory generator is responsible for switching between 
orbit and straight-line path following to maneuver the MAV along defined waypoints on the terrain map. The prepared simulation model provides a full flight MAV control system during various phases of flight and emulates commercial autopilots like MicroPilot [73] or Kestrel [74]. Simulation systems utilized during the MAV formation flight control tests were composed of two separate MAV blocks with autopilots (a full flight control system like the one presented in Figure 3): communication block which is responsible for data exchange between UAVs and a formation flight control block implementing a potential field leader following algorithm. The simulation model also takes into account positioning errors and noise in this process (not only the size of the GPS error but also the dynamic characteristics of the error. The GPS error model (both altitude and $x-y$ plane) includes a slowly varying, zero-mean bias ( $4.7 \mathrm{~m}$ for $\mathrm{x}$ and y direction, $9.2 \mathrm{~m}$ for altitude) and a random noise component ( $0.4 \mathrm{~m}$ for $\mathrm{x}$ and $\mathrm{y}$ direction, $0.7 \mathrm{~m}$ for altitude). The model of the transient behavior of the error was approximated using the Gauss-Markov process based on [75] with a standard deviation of $0.21 \mathrm{~m}$ in $\mathrm{x}$ and $\mathrm{y}$ directions and of $0.4 \mathrm{~m}$ in altitude. Moreover, the simulation model also took into account atmospheric disturbances. The total wind vector was represented as a constant vector (steady ambient wind) and stochastic process (wind gusts and atmospheric disturbances). A suitable approximation of the nonsteady gusts was given by Dryden transfer functions with turbulence intensities along vehicle frames $\mathrm{x}, \mathrm{y}, \mathrm{z}$ on level $2.12 \mathrm{~m}, 2.12 \mathrm{~m}$ and $1.4 \mathrm{~m}$ respectively for each direction [75]. A schematic of the entire system used within the study has been presented in Figure 4 .

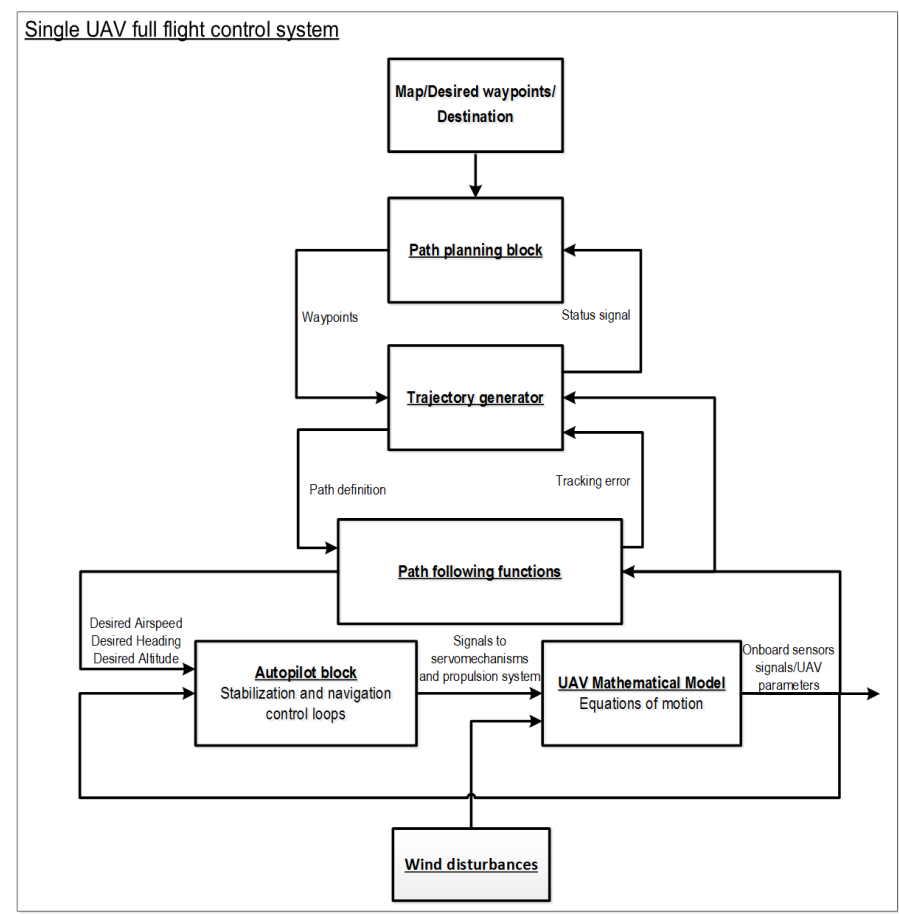

Figure 3. Single UAV control system architecture. 


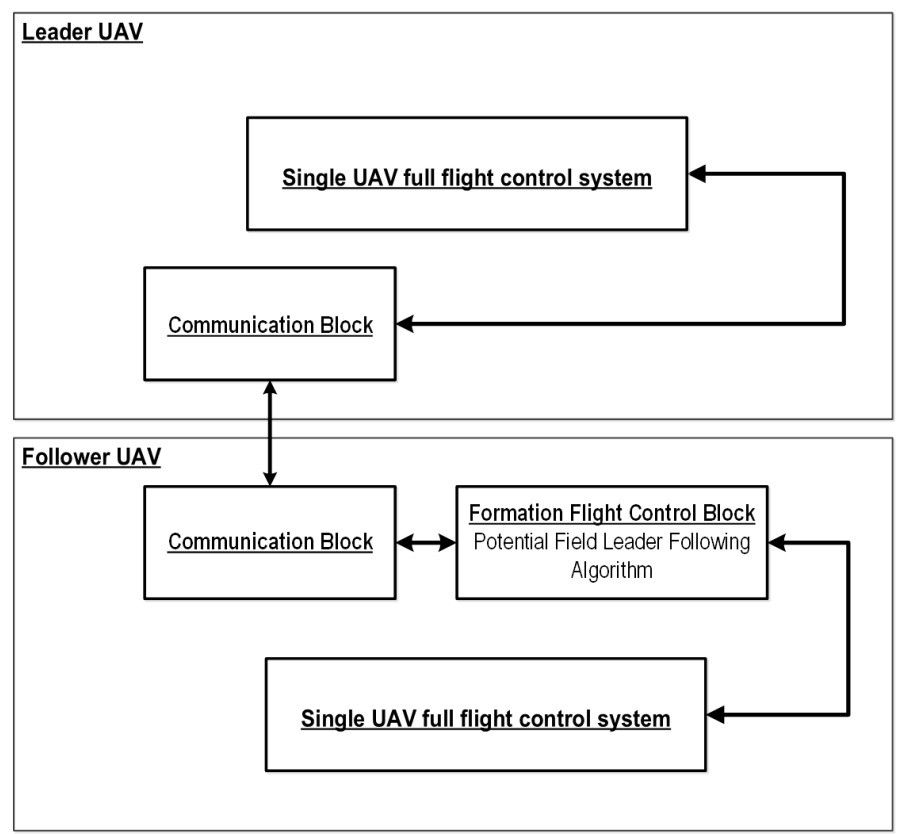

Figure 4. Simulation system architecture.

\section{Virtual Electric Dipole Field for Autonomous Formation Flight}

\subsection{Formation Flight Geometry}

The formation flight control system is based on the leader-follower control strategy. The cosidered example concerns the case of two UAVs-one leader and one follower. This is due to the fact that future in-flight tests of the proposed formation flight algorithm will be carried out with a single leader-follower scheme on account of consideration for available hardware resources (autopilots, airframes, base stations, etc.). A simple formation geometry of two UAVs is presented in Figure 5. Leader and follower positions can be denoted with the following formulas:

$$
\begin{aligned}
& L_{\text {pos }}=\left[\begin{array}{l}
x_{L} \\
y_{L} \\
z_{L}
\end{array}\right] . \\
& F_{p o s}=\left[\begin{array}{l}
x_{F} \\
y_{F} \\
z_{F}
\end{array}\right]
\end{aligned}
$$




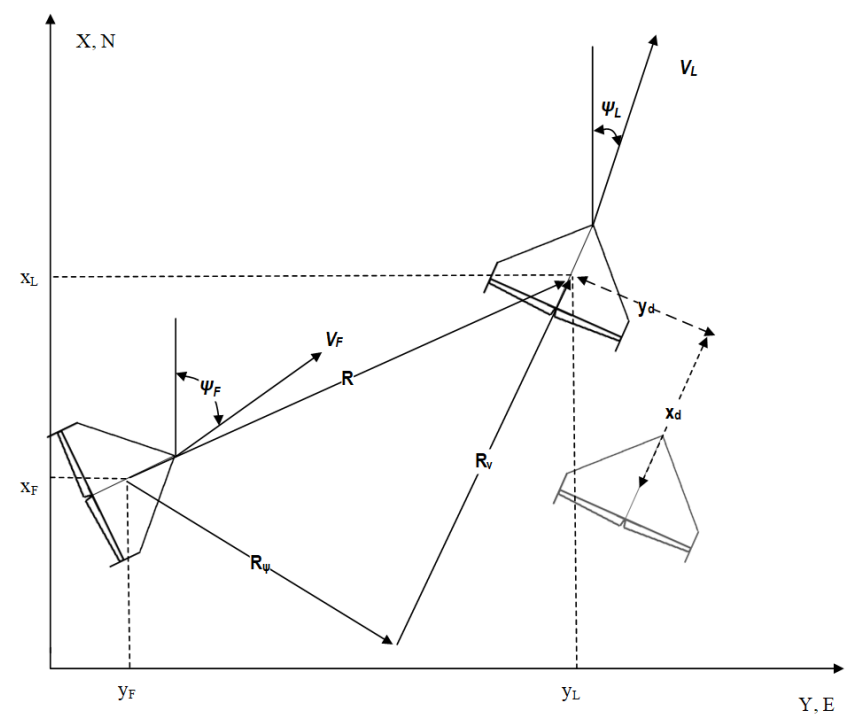

Figure 5. Formation flight geometry.

The length of $\mathbf{R}$ (defined on the scheme in Figure 5) is defined as:

$$
\|R\|=\sqrt{\left\|R_{\psi}\right\|+\left\|R_{v}\right\|} .
$$

The Follower UAV's commanded trajectory can be defined as:

$$
T_{F}^{c}=\left[\begin{array}{c}
V_{F}^{c} \\
\psi_{F}^{c} \\
A_{F}^{c}
\end{array}\right],
$$

where $V_{F}^{c}, \psi_{F}^{c}, A_{F}^{c}$ - is the follower's desired airspeed, heading and altitude respectively.

\subsection{Virtual Electric Dipole Field in Leader-Follower Control Structure}

The aim of the leader-follower formation control is to keep the follower in the desired position relative to the leader's position. Additionally, when the follower reaches the desired position, its heading should be parallel to the leader's heading. Therefore, the aim of formation flight control is to determine the heading and the velocity of the follower based on the leader's position and velocity. For the purposes of this paper, the potential field method, utilized first by Khatib [76] to help mobile robots to avoid obstacles, was used to determine the follower's heading angle. In later studies, the potential field method was used to plan the robot's paths, see e.g., [77-80]. The main idea of the potential field method is to find a scalar field whose gradient will produce the desired vector field in space. This virtual vector field is then used in the control process. The vector field used to control the follower's heading must have the following properties: lines of this field must meet at one point and reach this point in a manner that allows them to parallel the leader's velocity. The electric dipole whose dipole moment vector forms angle $\psi_{L}$ (leader heading) with the $\mathbf{x}$-axis and is, therefore, parallel to the longitudinal leader's velocity $\mathbf{V}_{L}$, is a good candidate for the generation of such a field. The electric vector field generated by the electric dipole is shown in Figure 6. 


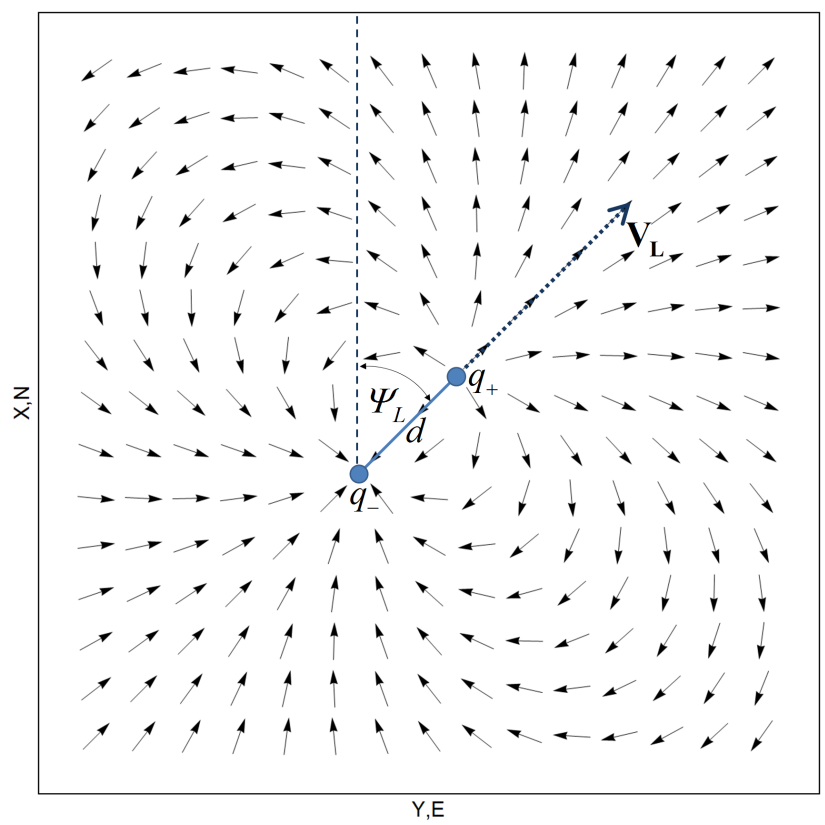

Figure 6. Electric dipole field.

The dipole electric field has the following features: the direction of the electric field is tangent to the field line at any point in space, the field lines begin on positive charge $q_{+}$and terminate on negative charge $q_{-}$, the field lines can never cross. When the direction of such an electric vector field defines the desired follower's heading, the path of the follower's UAV coincides with the field lines (the direction of the follower's velocity is determined by its heading, and by definition, the velocity is always tangent to the path). It can therefore be said that the position of charge $q_{-}$is an attractor for the follower, which ensures the stability of the system control. As can be seen in Figure 6, from almost any point within the space, the electric field lines reach point $q_{-}$circling the dipole. There is an exception, however, the part of space between dipole charges. In the case when the point $q_{-}$is the desired follower's position and the direction of the electric vector field defines the desired

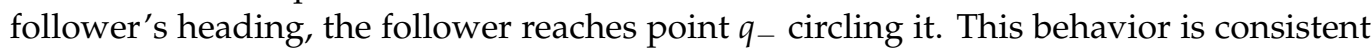
with intuition: if the electric dipole is placed in the leader position and $q_{-}$is the desired follower's position, the follower should just go around the leader and position behind him.

The follower's desired position relative to the leader's position can be arbitrary (the follower on the leader's right side, for example) and the virtual electric dipole position can also be arbitrary. The potential field of an exemplary leader-dipole configuration is shown in Figure 7.

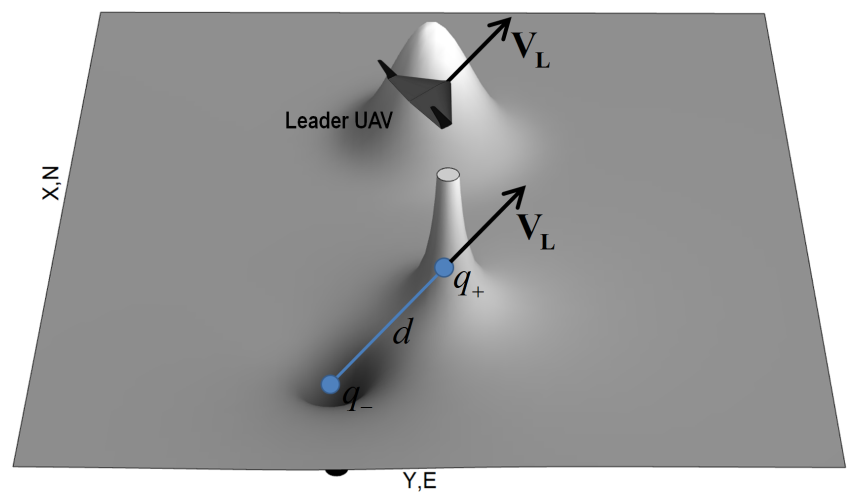

Figure 7. Lider-dipole potential field. 
Figure 7 also presents an additional potential field in the leader's position. This extra field creates a collision-preventing area protecting the leader from colliding with the follower.

\subsection{Potential Field Generation and Desired Heading Definition in Formation Flight}

Let the leader's position in the global frame in the plane YX be described by vector:

$$
R_{L}=\left(y_{L}, x_{L}\right),
$$

and the desired follower's position relative to the leader in the global frame by vector:

$$
R_{d}=\left(x_{d} \sin \left(\psi_{L}\right)+y_{d} \cos \left(\psi_{L}\right), x_{d} \cos \left(\psi_{L}\right)-y_{d} \sin \left(\psi_{L}\right)\right),
$$

where $\left(y_{d}, x_{d}\right)$-follower's desired position relative to the leader in the leader's body frame (please see Figure 5).

The follower's desired position in the global frame is described by vector:

$$
R_{d F}=R_{L}+R_{d}
$$

The electric field of the dipole has two singular points-these are points where electrical charges are placed. These are critical because within their proximity the vector field can rapidly change direction by as much as 180 degrees, changing the desired heading just as rapidly. The follower's desired position must not be placed at these critical points. The position of the negative charge of the electric dipole in the global frame is therefore described by the vector:

$$
R_{-}=R_{d F}+a\left(\sin \left(\psi_{L}\right), \cos \left(\psi_{L}\right)\right) .
$$

As can be seen in Equation (12), the position of the dipole's negative charge does not correspond to the follower's desired position (Equation (11)). Rather, the dipole's negative charge position is shifted in the direction of the leader's $\psi_{L}$ heading by a value of $a$ (see Figure 8). Position of the positive charge of the electric dipole in the global frame is described by a vector:

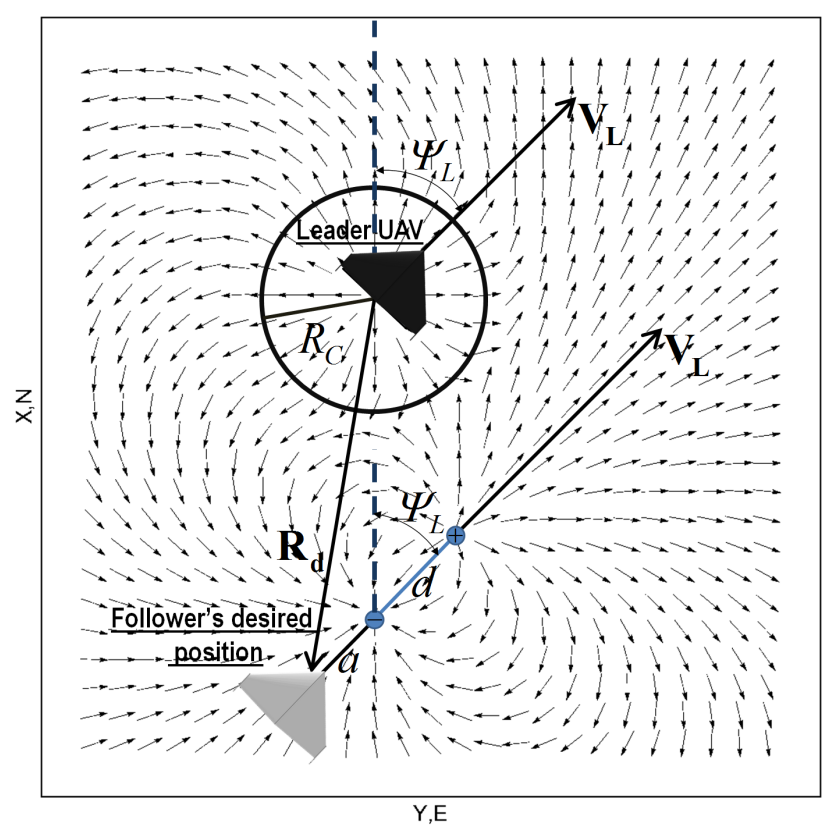

Figure 8. Exemplary vector field setting out the follower's heading. 


$$
R_{+}=R_{d F}+(d+a)\left(\sin \left(\psi_{L}\right), \cos \left(\psi_{L}\right)\right) .
$$

Based on the positions of the virtual electric charges (Equations (12) and (13)), it becomes possible to determine the potential field. A potential field generated by a positive charge at $(y, x)$ position is presented below:

$$
V_{+}=\frac{q_{c}}{\left\|R_{R+}\right\|},
$$

where: $R_{R+}=(y, x)-R_{+}, q_{c}$-is the electric charge value.

A negative charge generates the following potential field:

$$
V_{-}=\frac{-q_{c}}{\left\|R_{R-}\right\|},
$$

where $R_{R_{-}}=(y, x)-R_{-}$.

A potential field protecting the leader against a collision with the follower is expressed as:

$$
V_{C}=q_{c} \exp ^{\frac{-R_{R C}{ }^{2}}{C_{R C} C^{2}}}
$$

where $R_{R C}=(y, x)-R_{L}, R_{C}$ is the collision's radius, $C_{R C}$ is the collision's coefficient.

When $R_{R C}>R_{C}$, this protection field should disappear. It can be assumed that this happens in situations where $V_{C}$ is equal to 0.01 of its maximum value (equal to $q_{c}$ ). Under this assumption the collision's coefficient $C_{R C}$ is equal to 0.217 .

According to Equations (16) and (17) the total potential field at point $(y, x)$ takes the form of:

$$
V_{T}=V_{+}+V_{-}+V_{C}
$$

Taking into account Equations (9)-(16), Equation (17) can be written as:

$$
\begin{aligned}
& V_{T}=-\frac{q_{c}}{\sqrt{\left(a \cos \left(\psi_{L}\right)+x_{d} \cos \left(\psi_{L}\right)-y_{d} \sin \left(\psi_{L}\right)+x_{L}-x\right)^{2}+\left(a \sin \left(\psi_{L}\right)+x_{d} \sin \left(\psi_{L}\right)+y_{d} \cos \left(\psi_{L}\right)+y_{L}-y\right)^{2}}}+ \\
& \frac{q_{c}}{\sqrt{\left((a+d) \cos \left(\psi_{L}\right)+x_{d} \cos \left(\psi_{L}\right)-y_{d} \sin \left(\psi_{L}\right)+x_{L}-x\right)^{2}+\left((a+d) \sin \left(\psi_{L}\right)+x_{d} \sin \left(\psi_{L}\right)+y_{d} \cos \left(\psi_{L}\right)+y_{L}-y\right)^{2}}}+ \\
& q_{c} \exp ^{-\frac{\left(x-x_{L}\right)^{2}\left(y-y_{L}\right)^{2}}{R_{C}^{2} C_{R C}}}
\end{aligned}
$$

The next step is to determine the vector field based on the scalar potential field (18). The vector field for controlling follower's heading is determined using the following formula:

$$
E_{T}=\left(E_{y}, E_{x}\right)=-\operatorname{grad} V_{T}
$$
form of:

Taking into account Equations (18) and (19), components of the vector field take the

$$
\begin{aligned}
& E_{y}=\frac{q_{c}\left(a \sin \left(\psi_{L}\right)+x_{d} \sin \left(\psi_{L}\right)+y_{d} \cos \left(\psi_{L}\right)+y_{L}-y\right)}{\left(\left(a \cos \left(\psi_{L}\right)+x_{d} \cos \left(\psi_{L}\right)-y_{d} \sin \left(\psi_{L}\right)+x_{L}-x\right)^{2}+\left(a \sin \left(\psi_{L}\right)+x_{d} \sin \left(\psi_{L}\right)+y_{d} \cos \left(\psi_{L}\right)+y_{L}-y\right)^{2}\right)^{3 / 2}}- \\
& \frac{q_{c}\left((a+d) \sin \left(\psi_{L}\right)+x_{d} \sin \left(\psi_{L}\right)+y_{d} \cos \left(\psi_{L}\right)+y_{L}-y\right)}{\left(\left((a+d) \cos \left(\psi_{L}\right)+x_{d} \cos \left(\psi_{L}\right)-y_{d} \sin \left(\psi_{L}\right)+x_{L}-x\right)^{2}+\left((a+d) \sin \left(\psi_{L}\right)+x_{d} \sin \left(\psi_{L}\right)+y_{d} \cos \left(\psi_{L}\right)+y_{L}-y\right)^{2}\right)^{3 / 2}}+ \\
& \frac{2 q_{c}\left(y-y_{L}\right) \mathrm{e}^{-\frac{\left(x-x_{L}\right)^{2}+\left(y-y_{L}\right)^{2}}{R_{C}^{2} C_{R C}}}}{R_{C}^{2} C_{R C}} \\
& E_{x}=\frac{q_{c}\left(a \cos \left(\psi_{L}\right)+x_{d} \cos \left(\psi_{L}\right)-y_{d} \sin \left(\psi_{L}\right)+x_{L}-x\right)}{\left(\left(a \cos \left(\psi_{L}\right)+x_{d} \cos \left(\psi_{L}\right)-y_{d} \sin \left(\psi_{L}\right)+x_{L}-x\right)^{2}+\left(a \sin \left(\psi_{L}\right)+x_{d} \sin \left(\psi_{L}\right)+y_{d} \cos \left(\psi_{L}\right)+y_{L}-y\right)^{2}\right)^{3 / 2}}- \\
& \frac{q_{c}\left((a+d) \cos \left(\psi_{L}\right)+x_{d} \cos \left(\psi_{L}\right)-y_{d} \sin \left(\psi_{L}\right)+x_{L}-x\right)}{\left(\left((a+d) \cos \left(\psi_{L}\right)+x_{d} \cos \left(\psi_{L}\right)-y_{d} \sin \left(\psi_{L}\right)+x_{L}-x\right)^{2}+\left((a+d) \sin \left(\psi_{L}\right)+x_{d} \sin \left(\psi_{L}\right)+y_{d} \cos \left(\psi_{L}\right)+y_{L}-y\right)^{2}\right)^{3 / 2}}+ \\
& \frac{2 q_{c}\left(x-x_{L}\right) \mathrm{e}^{-\frac{\left(x-x_{L}\right)^{2}+\left(y-y_{L}\right)^{2}}{R_{C}^{2} C_{R C}}}}{R_{C}^{2} C_{R C}}
\end{aligned}
$$


The vector field $E_{T}$ has been used to control the follower's heading. Finally, the angle between vector $E_{T}$ and the positive $X, N$-axis in the follower's position define the follower's desired heading:

$$
\psi_{F}^{c}=\angle\left(X, N, E_{T}\right) .
$$

An exemplary vector field setting out the follower's heading is shown in Figure 8. In conclusion, it should be emphasized that the proposed vector field has one big advantage: a lack of local minima and only one global minimum in the position of the negative charge (minus infinity). The absence of additional minima makes control processes using such potential fields reliable because such control systems have only one attractor.

\subsection{Velocity Control in Formation Flight}

Realization of effective formation flights also requires precise control over the follower UAV's velocity. In the approach presented within this work, velocity control is based on position errors between the leader and the follower. These position errors can be defined as follows:

$$
e_{x y z}=L_{p o s}-F_{p o s}=\left[\begin{array}{c}
x_{L} \\
y_{L} \\
z_{L}
\end{array}\right]-\left[\begin{array}{c}
x_{F} \\
y_{F} \\
z_{F}
\end{array}\right]=\left[\begin{array}{c}
e_{x} \\
e_{y} \\
e_{z}
\end{array}\right] .
$$

Errors defined in Equation (22) need to be expressed in the formation frame. In the formation frame they can be written as follows:

$$
\begin{gathered}
\left\|R_{v}\right\|=\sin \psi_{L} e_{x}+\cos \psi_{L} e_{y}, \\
\left\|R_{\psi}\right\|=\cos \psi_{L} e_{x}-\sin \psi_{L} e_{y} .
\end{gathered}
$$

Position errors expressed in the formation frame in $\mathrm{x}$ and $\mathrm{y}$ directions are defined as $\left\|R_{v}\right\|(23)$ and $\left\|R_{\psi}\right\|$ (24). To control the follower's velocity during formation flight only the $R_{v}$ component of the vector $R$ is used. The position error $\left\|R_{v}\right\|$ expressed in the formation frame defined with Equation (23) should contain the desired distance in direction $\mathrm{x}$ designated as $x_{d}$. This can be expressed in the following manner:

$$
e_{v}=\left\|R_{v}\right\|-x_{d}=\left[\sin \psi_{L} e_{x}+\cos \psi_{L} e_{y}\right]-x_{d}
$$

Parameter $e_{v}$ is the input signal to the velocity controller (please refer to scheme in Figure 9). Discrete time forms of the controller for producing airspeed corrections are presented below:

$$
u_{v}=k_{p}+k_{d} \frac{N}{1+N \frac{T_{s}}{2} \frac{\mathcal{Z}+1}{\mathcal{Z}-1}},
$$

where $k_{p}, k_{d}$ are controller gains, $T_{s}$ is sampling time, $N$ is the filter coefficient, $\mathcal{Z}$ is a discrete time operator from $\mathcal{Z}$ transform.

During formation flight control the desired altitude signal for the follower UAV is produced in accordance with the following equation:

$$
A_{F}^{c}=A_{L}^{c}+z_{d}
$$

where $z_{d}$ is the desired separation distance in direction $z$. 


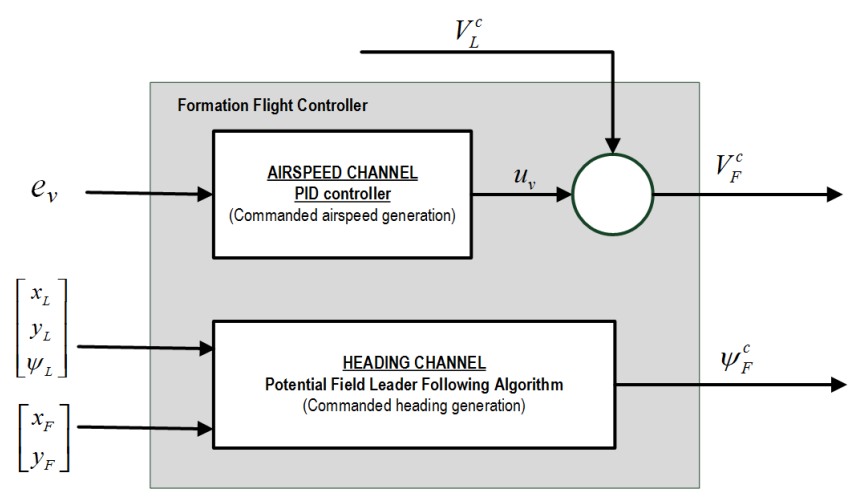

Figure 9. Formation flight controller scheme.

\section{Results}

Simulation tests of the proposed formation flight control algorithm were performed with one leader and one follower. The leader had information about the desired trajectory. The follower's task was to follow the leader using the potential field algorithm. Performed tests were done using straight-line path following as well as the loiter function (following a circular path with a specified radius). Initial parameters (positions, headings) of the leader and the follower were different and were changed during the tests (please refer to Tables 4 and 5). Other parameters utilized in the Equation (20) were: $R_{C}=20 \mathrm{~m}$, $C_{R C}=0.217, a=20 \mathrm{~m}, d=20 \mathrm{~m}, q_{c}=1$. During simulation tests MAVs dynamics were influenced by atmospheric disturbances $V_{\text {wind }}=V_{w_{\text {const }}}+V_{w_{d y n}}$ modeled as constant wind field $V_{w_{\text {const }}}=\left[\begin{array}{ccc}w_{x} & w_{y} & w_{z}\end{array}\right]^{T}$ (where $w_{x}=1 \mathrm{~m} / \mathrm{s}, w_{y}=3 \mathrm{~m} / \mathrm{s}, w_{z}=0 \mathrm{~m} / \mathrm{s}$ ) expressed in the inertial frame with added turbulences $V_{w_{d y n}}$ (non-steady gusts). The turbulences $V_{w_{d y n}}$ were generated by passing white noise signal through Dryden transfer functions. Dryden gust model parameters were taken for low altitudes and moderate turbulences in accordance to [64]. Simulation studies include seven test flights (four tests for straight-line and three for circle path).

\subsection{Straight Line Path Following Tests}

During straight-line path following tests, the follower had to fly $30 \mathrm{~m}$ behind the leader and $15 \mathrm{~m}$ to its left side. The first trial concerned the situation when the follower's initial position was placed $100 \mathrm{~m}$ behind the leader (Figure 10). During trials, two and three, the follower's initial position was set $200 \mathrm{~m}$ to the left of and to the right of the leader (Figures 11 and 12). The fourth test concerned the situation when the follower's initial position was in front of the leader with the two given opposite headings to provoke a potential collision (Figures 13 and 14). During all tests vector $\mathbf{R}$ was measured and presented to confirm the quality of the formation flight control system.

Table 4. Initial parameters during simulation tests with using straight line path.

\begin{tabular}{|c|c|c|c|c|c|c|c|c|c|c|}
\hline \multirow{2}{*}{$\begin{array}{l}\text { Test } \\
\text { Number }\end{array}$} & \multicolumn{2}{|c|}{$\begin{array}{l}\text { Leader Initial } \\
\text { Positions }\left(L_{p o s}\right)\end{array}$} & \multicolumn{4}{|c|}{$\begin{array}{l}\text { Follower Initial } \\
\text { Positions }\left(F_{p o s}\right)\end{array}$} & \multicolumn{2}{|c|}{$\begin{array}{l}\text { Desired Distances } \\
\text { during Formation } \\
\text { Flight }\end{array}$} & \multicolumn{2}{|c|}{$\begin{array}{l}\text { Initial } \\
\text { Headings }\end{array}$} \\
\hline & $\begin{array}{c}x_{L} \\
{[\mathrm{~m}]}\end{array}$ & $\begin{array}{c}y_{L} \\
{[\mathrm{~m}]}\end{array}$ & $\begin{array}{c}z_{L} \\
{[\mathrm{~m}]}\end{array}$ & $\begin{array}{c}x_{F} \\
{[\mathrm{~m}]}\end{array}$ & $\begin{array}{c}y_{F} \\
{[\mathrm{~m}]}\end{array}$ & $\begin{array}{c}z_{F} \\
{[\mathrm{~m}]}\end{array}$ & $\begin{array}{c}x_{d} \\
{[\mathrm{~m}]}\end{array}$ & $\begin{array}{c}y_{d} \\
{[\mathrm{~m}]}\end{array}$ & $\underset{[\mathrm{rad}]}{\psi_{L}}$ & $\underset{[\mathrm{rad}]}{\psi_{F}}$ \\
\hline 1 & 100 & 0 & 100 & 0 & 0 & 100 & -30 & -15 & 0 & 0 \\
\hline 2 & 100 & 0 & 100 & 0 & 200 & 100 & -30 & -15 & 0 & 0 \\
\hline 3 & 100 & 0 & 100 & 0 & -200 & 100 & -30 & -15 & 0 & 0 \\
\hline 4 & 0 & 0 & 100 & 100 & 0 & 100 & -30 & -15 & 0 & $\pi$ \\
\hline
\end{tabular}




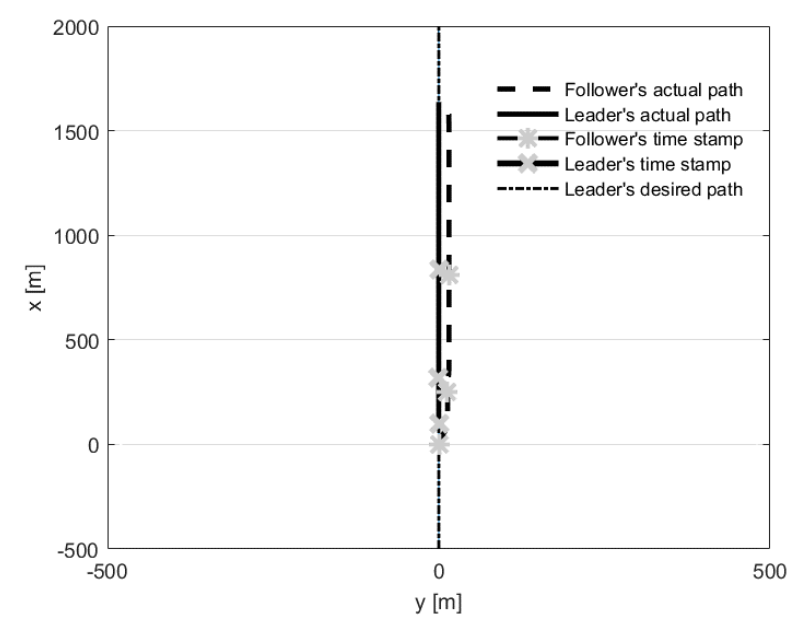

(a) trajectories

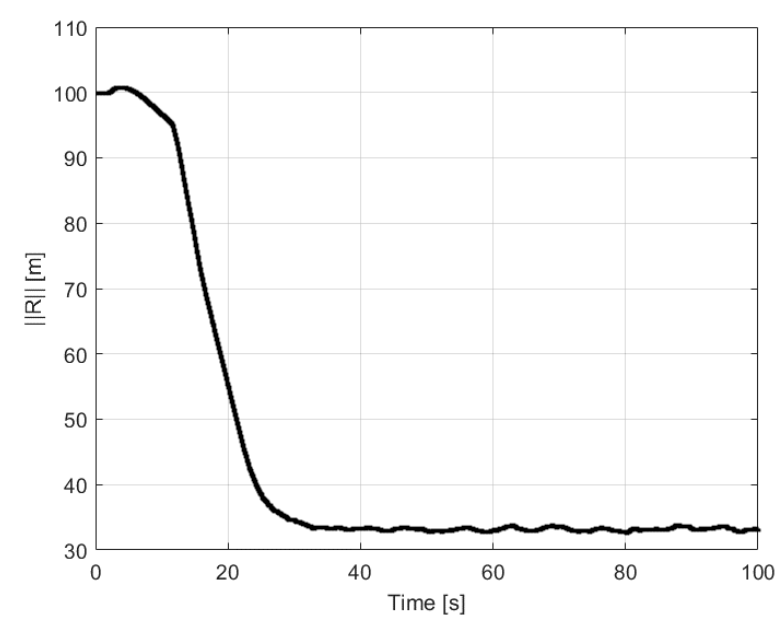

(b) parameter $\|R\|$

Figure 10. UAVs positions during formation flight for Test 1: (a) trajectories, (b) parameter $\|R\|$.

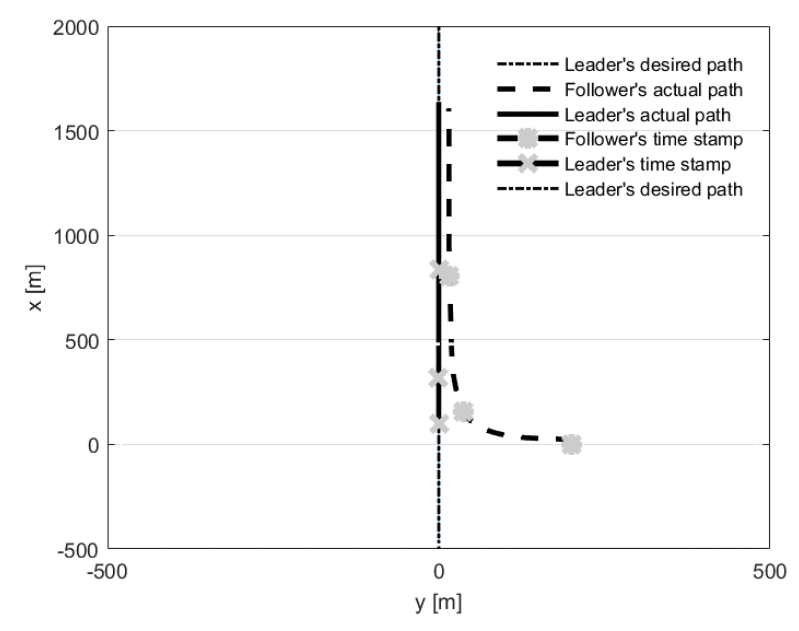

(a) trajectories

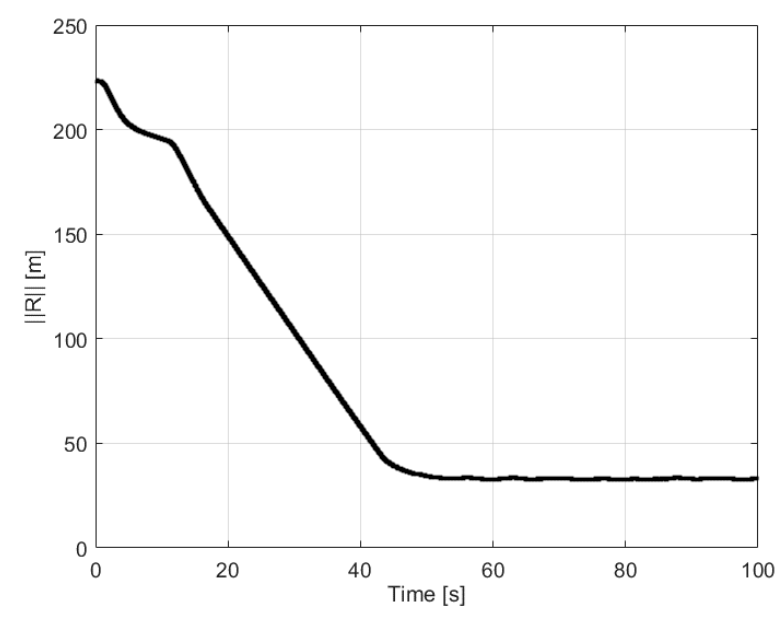

(b) parameter $\|R\|$

Figure 11. UAVs positions during formation flight for Test 2: (a) trajectories, (b) parameter $\|R\|$.

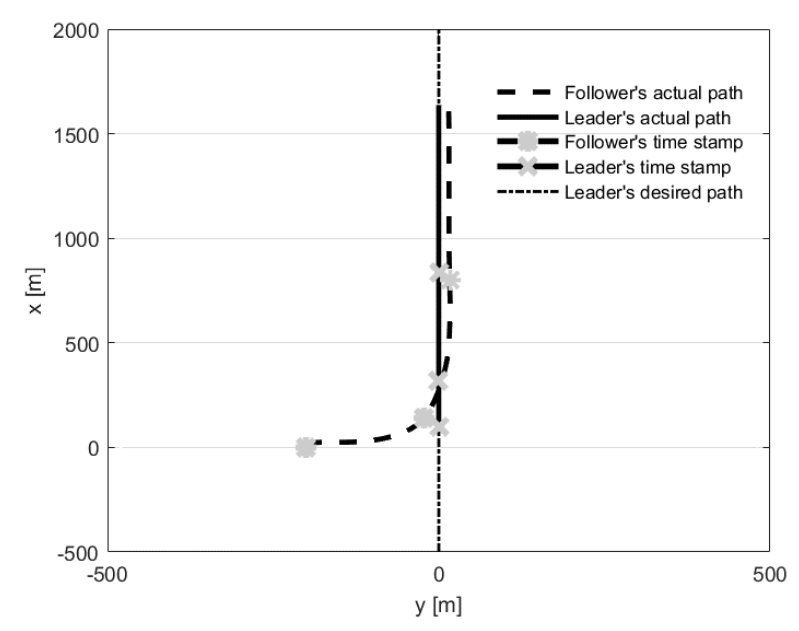

(a) trajectories

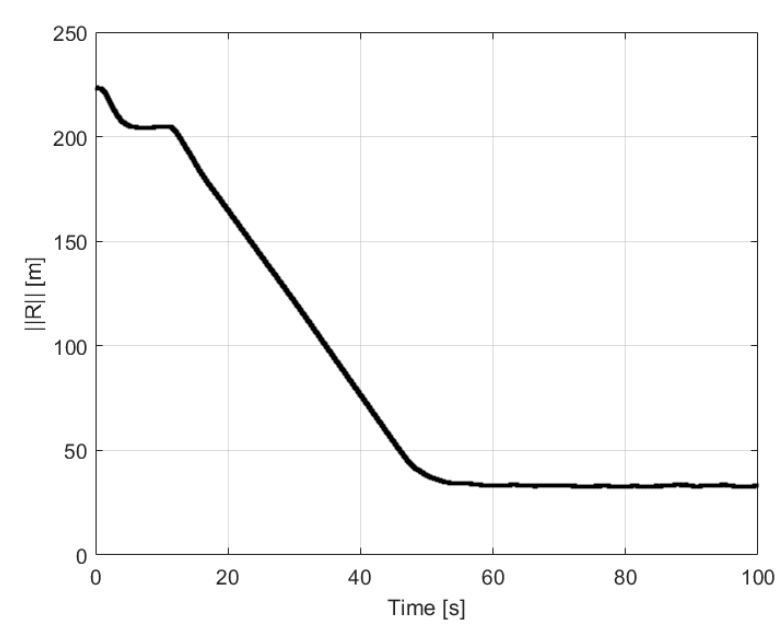

(b) parameter $\|R\|$

Figure 12. UAVs positions during formation flight for Test 3: (a) trajectories, (b) parameter $\|R\|$. 


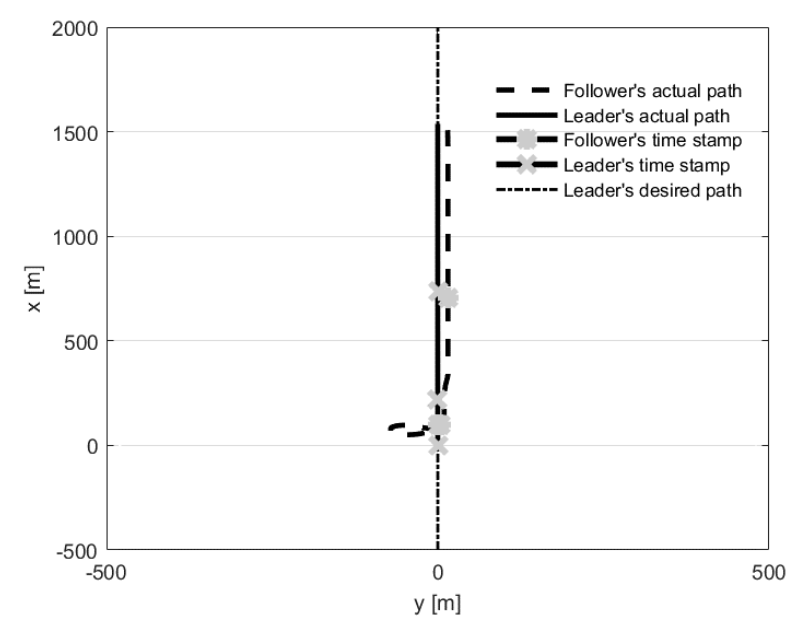

(a) trajectories

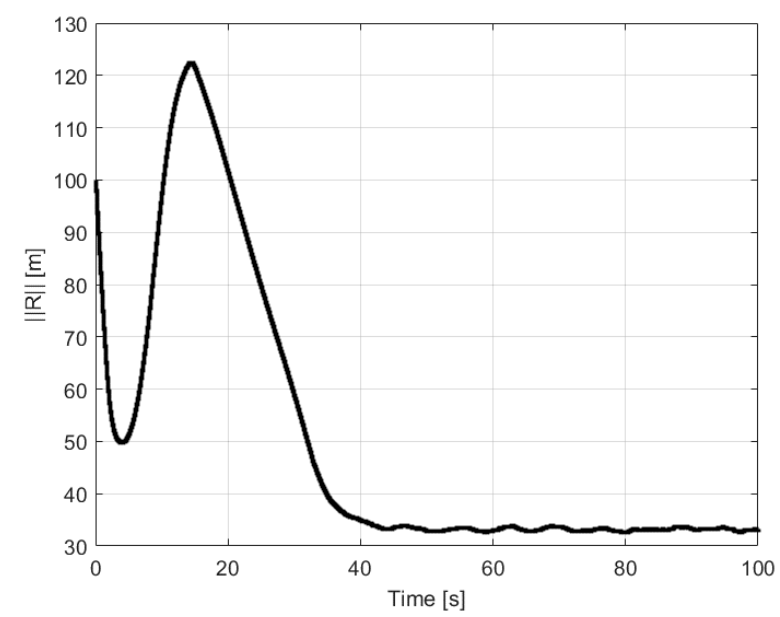

(b) parameter $\|R\|$

Figure 13. UAVs positions during formation flight for Test 4: (a) trajectories, (b) parameter $\|R\|$.

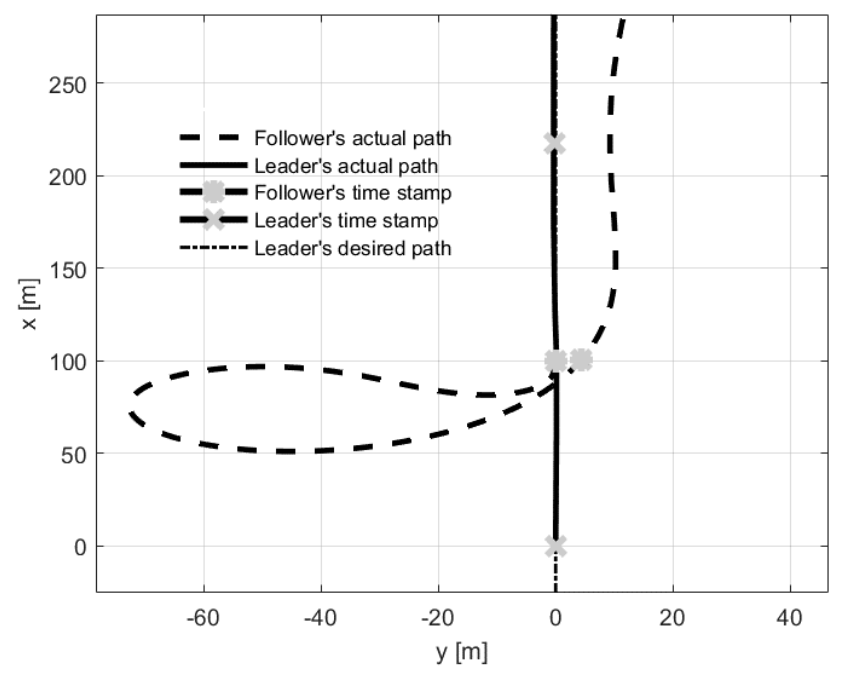

Figure 14. Test 4: leader's and follower's trajectories during formation flight-zoom in.

\subsection{Circle Path Following Tests}

The second portion of simulation tests was associated with following a circular path. The first loitering trial concerned a situation where the follower had to fly behind the leader at a distance of $30 \mathrm{~m}$ as well as $15 \mathrm{~m}$ to its left. Initial headings of the leader and the follower were the same and were equal to 0 rad. The leader's initial position was in front of the follower. Figure 15 shows the paths of the leader and the follower during trial 5 . To show the quality of formation flight control, the length of vector $\mathbf{R}$ has also been presented. Test 5 concerned a case when the follower's initial position was behind the leader (with both having the same initial headings). The follower's behavior could easily be predicted-the follower caught up with the leader and then fell into the desired position.

Test number 6 concerned a situation when the leader's initial position was behind the follower (with both having the same desired separation distance). Results of this attempt are shown in Figure 16. The follower's heading is determined by an electric vector field generated by a virtual electric dipole (see Figure 8), so at the beginning, the follower turned left, next it made a circle and settled behind the leader in the desired position. This behavior is consistent with one's intuition. Test number 7 presented a case where the leader's and follower's initial headings were opposite. Figures 17 and 18 show the results of this test. In this case, the follower's behavior is similar to test 6 - the follower first turned left and 
next made a circle. For the circle trajectory following, an additional test (number 8) was performed in which the desired altitude of the leader and follower were different, while the follower follows the leader without position shifting respect the leader on the $x-y$ plane. The results are presented in the form of a 3D trajectory and its projection on the $\mathrm{x}-\mathrm{y}$ plane (Figure 19 as well as a time course of the $\|R\|$ parameter (Figure 20).

Table 5. Initial parameters during simulation tests with using circle path.

\begin{tabular}{|c|c|c|c|c|c|c|c|c|c|c|c|}
\hline \multirow{2}{*}{$\begin{array}{l}\text { Test } \\
\text { Number }\end{array}$} & \multicolumn{2}{|c|}{$\begin{array}{l}\text { Leader Initial } \\
\text { Positions }\left(L_{p o s}\right)\end{array}$} & \multirow[b]{2}{*}{$\begin{array}{c}z_{L} \\
{[\mathrm{~m}]}\end{array}$} & \multicolumn{3}{|c|}{$\begin{array}{l}\text { Follower Initial } \\
\text { Positions }\left(F_{p o s}\right)\end{array}$} & \multicolumn{2}{|c|}{$\begin{array}{l}\text { Desired Distances } \\
\text { during Formation } \\
\text { Flight }\end{array}$} & \multirow[b]{2}{*}{$\begin{array}{c}z_{d} \\
{[\mathrm{~m}]}\end{array}$} & \multicolumn{2}{|c|}{$\begin{array}{l}\text { Initial } \\
\text { Headings }\end{array}$} \\
\hline & $\begin{array}{c}x_{L} \\
{[\mathrm{~m}]}\end{array}$ & $\begin{array}{c}y_{L} \\
{[\mathrm{~m}]}\end{array}$ & & $\begin{array}{c}x_{F} \\
{[\mathrm{~m}]}\end{array}$ & $\begin{array}{c}y_{F} \\
{[\mathrm{~m}]}\end{array}$ & $\begin{array}{c}z_{F} \\
{[\mathrm{~m}]}\end{array}$ & $\begin{array}{c}x_{d} \\
{[\mathrm{~m}]}\end{array}$ & $\begin{array}{c}y_{d} \\
{[\mathrm{~m}]}\end{array}$ & & $\underset{[\mathrm{rad}]}{\psi_{L}}$ & $\underset{[\mathrm{rad}]}{\psi_{F}}$ \\
\hline 5 & 100 & 0 & 100 & 0 & 0 & 100 & -30 & -15 & 0 & 0 & 0 \\
\hline 6 & 0 & 0 & 100 & 100 & 0 & 100 & -30 & -15 & 0 & 0 & 0 \\
\hline 7 & 0 & 0 & 100 & 100 & 0 & 100 & -30 & -15 & 0 & 0 & $\pi$ \\
\hline 8 & 100 & 0 & 100 & 0 & 0 & 100 & -50 & 0 & -10 & 0 & 0 \\
\hline
\end{tabular}

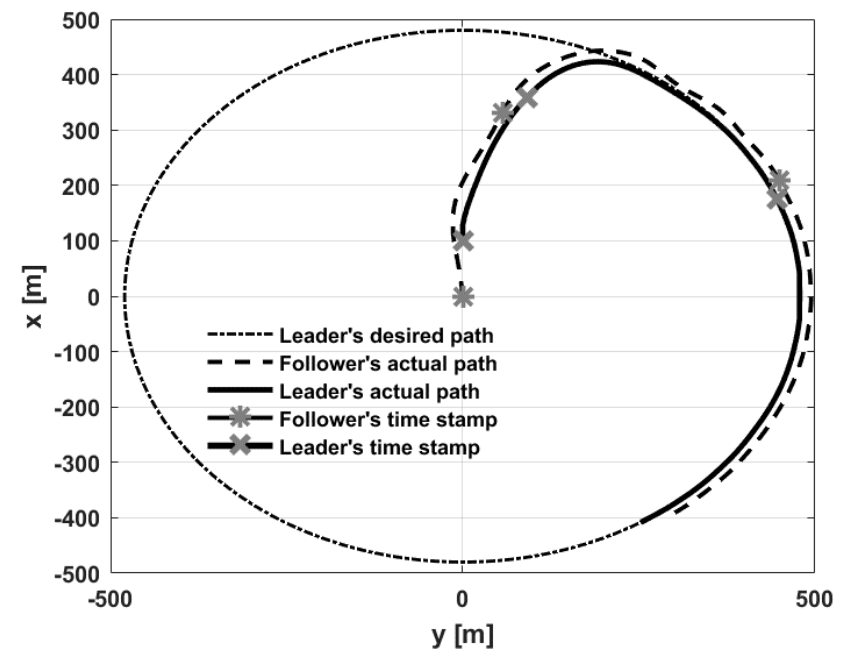

(a) trajectories

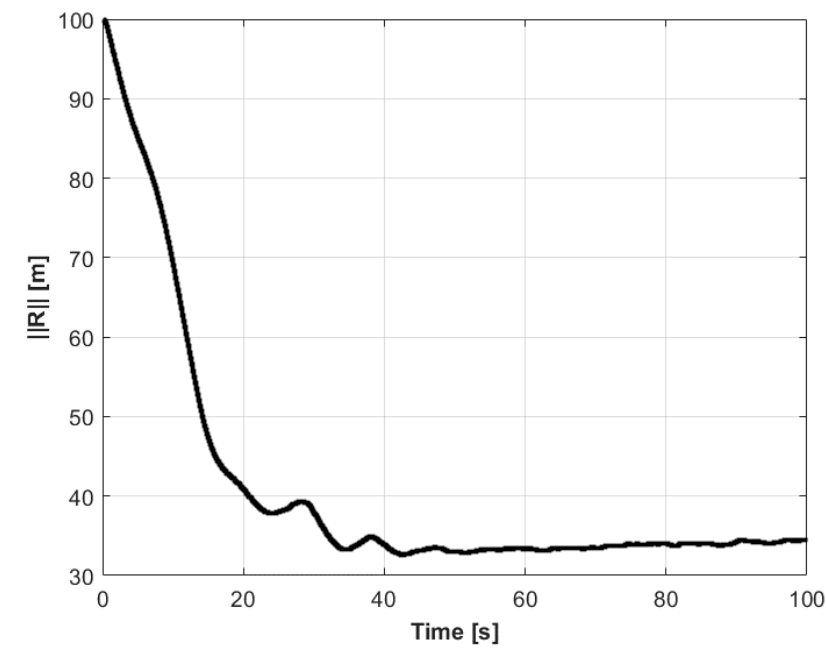

(b) parameter $\|R\|$

Figure 15. UAVs positions during formation flight for Test 5: (a) trajectories, (b) parameter $\|R\|$.

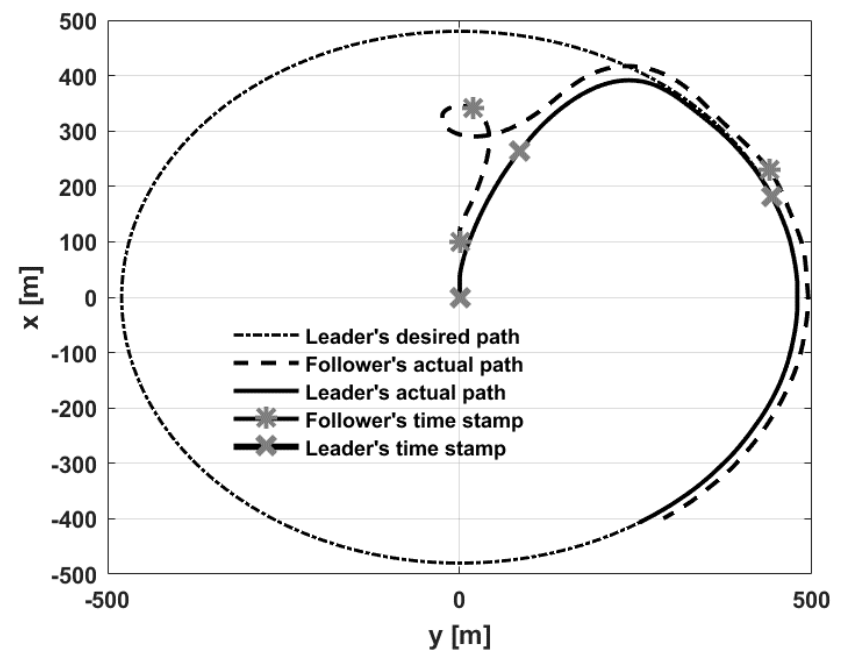

(a) trajectories

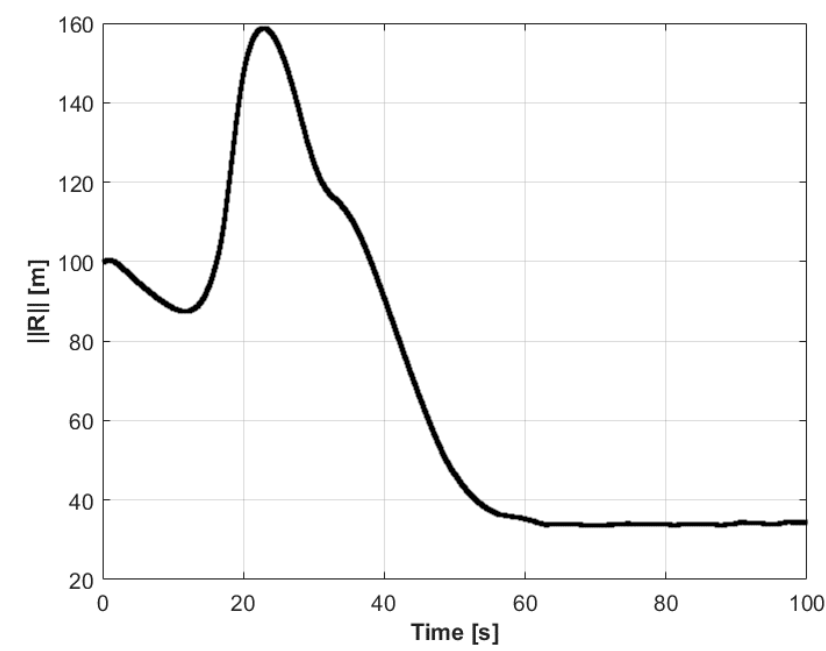

(b) parameter $\|R\|$

Figure 16. UAVs positions during formation flight for Test 6: (a) trajectories, (b) parameter $\|R\|$. 


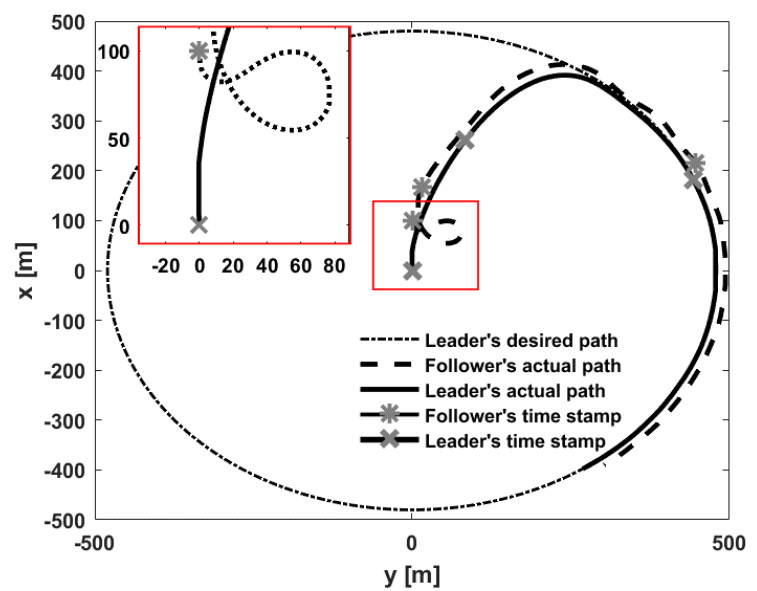

(a) trajectories

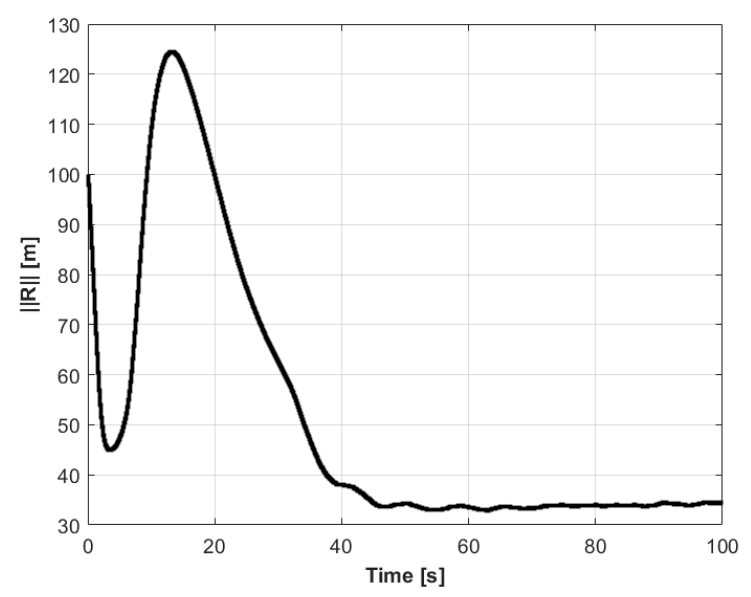

(b) parameter $\|R\|$

Figure 17. UAVs positions during formation flight for Test 7: (a) trajectories, (b) parameter $\|R\|$.

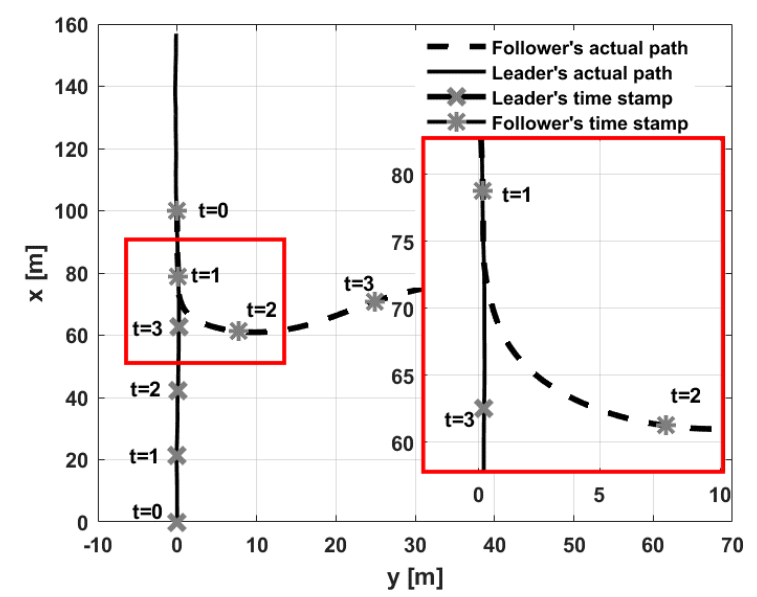

(a) trajectories

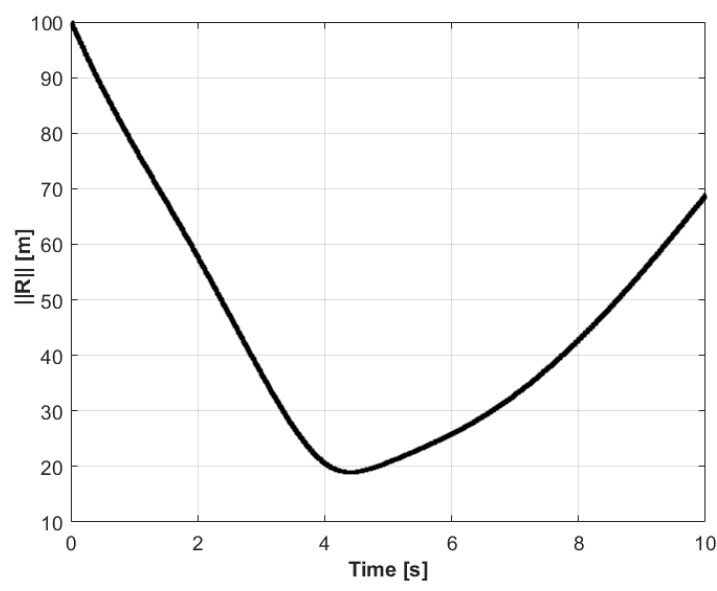

(b) parameter $\|R\|$

Figure 18. UAVs positions during test for Test 7—collision avoidance: (a) trajectories, (b) parameter $\|R\|$.

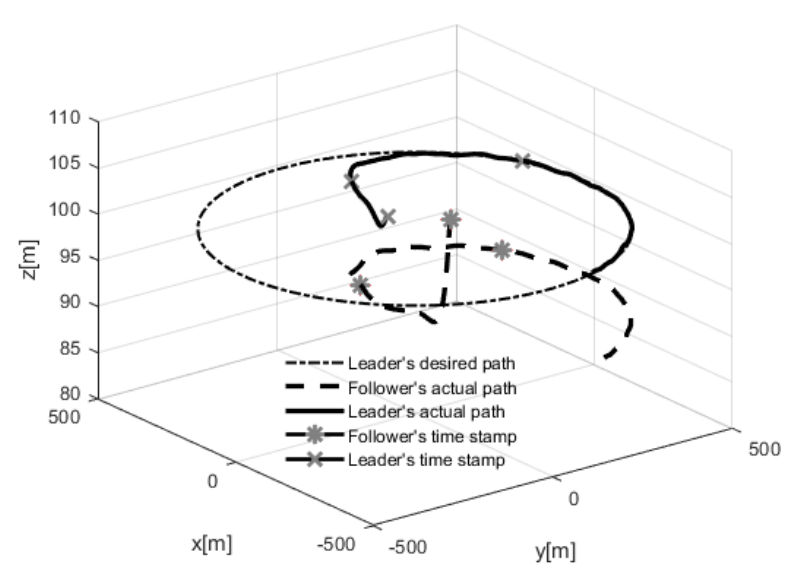

(a) 3D trajectories

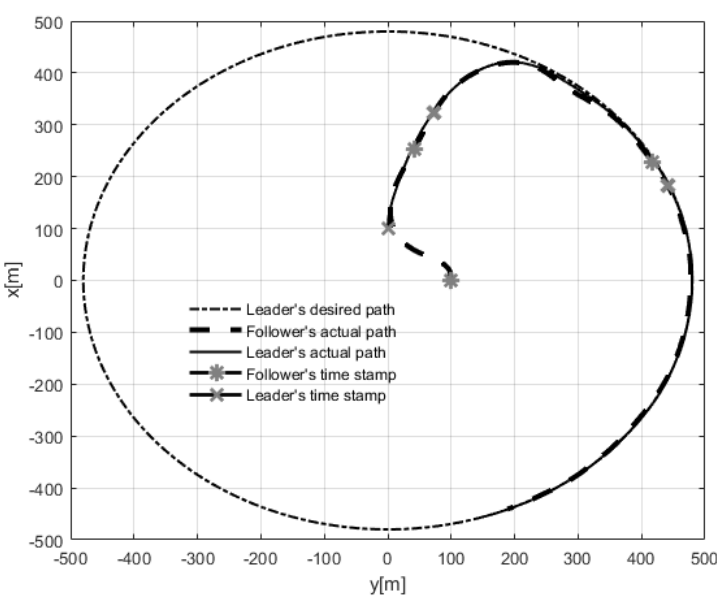

(b) 2D trajectories

Figure 19. UAVs positions during test for Test 8: (a) 3D trajectories, (b) 2D trajectories. 


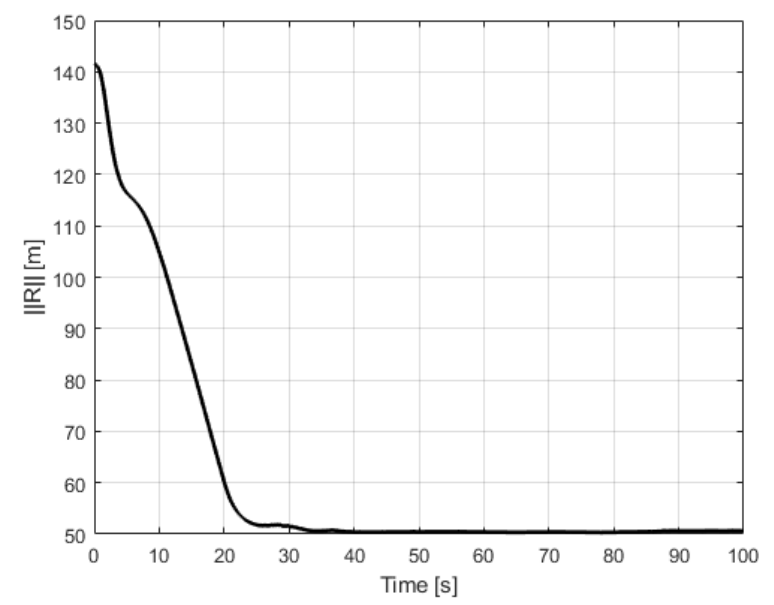

Figure 20. UAVs positions during test for Test 8: parameter $\|R\|$.

Simulation tests also verified the collision avoidance efficiency of the proposed algorithm. In Equation (17) the part related to the formation flight was turned off $\left(V_{+}=V_{-}=0\right)$. Only the component responsible for collision avoidance was left active. The leader and the follower were installed $100 \mathrm{~m}$ apart and given opposite headings ( $0 \mathrm{rad}$ and $\pi \mathrm{rad}$ ). Both UAVs had to follow the same straight line to create a likelihood of a collision situation. The results of this test have been presented in the Figures 13, 17 and 18. An analysis of the follower's trajectory shows no collision occurred. The follower deviated from its established path and avoided a collision with the second UAV. During the test, the $\|R\|$ parameter value decreased to about $20 \mathrm{~m}$ indicating that distance as the closest proximity of the UAVs. Furthermore, this distance can be modified through parameter $R_{C}$. The most convenient way to check the quality of the proposed algorithm is to determine some statistical parameters. For flight tests $1-7$, the root mean square error (RMSE) and relative root mean square error (RRMSE ) between the desired and the real follower's position were determined. These indicators were calculated for the $\|R\|$ parameter logged during $100 \mathrm{sec}$ long simulations. For RMSE and RRMSE calculations, only the last 30sec of data were used to ensure that the transient process expired and both UAVs positions were set properly. Established indicators have been presented in Table 6.

Table 6. Statistical parameters of the simulation results.

\begin{tabular}{ccc}
\hline Test Number & RMSE [m] & RRMSE [\%] \\
\hline 1 & 0.2238 & 0.6672 \\
2 & 0.2339 & 0.6974 \\
3 & 0.2376 & 0.7084 \\
4 & 0.2289 & 0.6824 \\
5 & 0.2790 & 0.8318 \\
6 & 0.2641 & 0.7874 \\
7 & 0.2800 & 0.8348 \\
\hline
\end{tabular}

Concerning the existence of random wind, the accuracy of the MAV model, quality of the composed simulation system, and the leader's nonlinear motion (circular path following) an error of approximately $30 \mathrm{~cm}$ can be considered to be a satisfactory result. The influence of random wind and inaccuracies of GNSS measurements can also be observed in figures labeled as "parameter $\|R\|$ during flight" where the parameter $\mathrm{R}$ performs small oscillations. Additionally, during the simulation tests, the impact of the communication delay between leader and follower was checked. During the straight-line path following the communication delay was changed from $0.1 \mathrm{~s}$ to $2.0 \mathrm{~s}$ and the RMSE and RRMSE were calculated from the last $30 \mathrm{~s}$ of $100 \mathrm{~s}$ long simulations (Table 7). It can be easily noticed that 
the RMSE and RRMSE parameters grow along with a rise in the time delay. In the case of the circle path following the communication delay over $2 \mathrm{~s}$ was a critical value and caused the follower not to reach its desired position behind the leader.

Table 7. Statistical parameters of the simulation results with communication delay.

\begin{tabular}{ccc}
\hline Communication Time Delay [sec] & RMSE [m] & RRMSE [\%] \\
\hline 0.1 & 1.1602 & 3.4590 \\
0.5 & 1.2438 & 3.7083 \\
1.0 & 1.3407 & 3.9972 \\
1.5 & 1.4736 & 4.3934 \\
2.0 & 1.5844 & 4.7238 \\
\hline
\end{tabular}

\section{Conclusions}

The paper presents a new method for controlling the formation flight of Unmanned Aerial Vehicles (UAVs). The control algorithm proposed within the work uses a virtual electric dipole field to determine a desired heading for the follower UAV. Furthermore, the manner of potential field generation provides protection from collisions during operations employing multiple UAVs. Simulation results presented in Chapter 4 are promising. A major advantage of using an electric field generated by a virtual electric dipole is its universality, reliability, and the fact that the follower's heading is determined directly and not as corrections from the controller. This new method eliminates the need for a mixed control strategy since it works correctly within the entire phase space of the leader-follower system. One disadvantage of the presented method might be the computational complexity of the control algorithm. However, it should be noted that the computational resources of UAVs are constantly growing, and small, lightweight, high-performance on-module computers with low power consumption are available. Yet another disadvantage of the proposed system is that the follower's velocity control strategy is different from its heading control. Achievement of a unified system for the control of the follower's heading and velocity will be the subject of further research. The authors also plan to expand research into systems with more than one follower. Possibilities for changing formation flight hierarchy (where the leader becomes the follower and the follower becomes the leader) may also become the focus of future studies. It is worth mentioning that the described algorithm was successfully verified during in-flight tests, the results of which will be presented in the following article.

Author Contributions: conceptualization, L.A. and M.C.; methodology, L.A.; software, L.A.; validation, L.A.; formal analysis, L.A. and M.C.; investigation, L.A.; resources, L.A.; data curation, L.A.; writing-original draft preparation, L.A.; writing-review and editing, L.A.; visualization, L.A.; supervision, L.A.; project administration, L.A.; funding acquisition, L.A. All authors have read and agreed to the published version of the manuscript.

Funding: The research work has been carried out in the framework of works No. WZ/WM-IIM/1/2019 and WZ/WE-IA/4/2020 at the Bialystok University of Technology and financed from the funds for science by the Polish Ministry of Science and Higher Education.

Institutional Review Board Statement: Not applicable.

Informed Consent Statement: Not applicable.

Data Availability Statement: Not applicable.

Conflicts of Interest: The authors declare no conflict of interest.

\section{References}

1. Gundlach, G. Designing Unmanned Aircraft Systems: A Comprehensive Approach; AIAA Education Series; American Institute of Aeronautics and Astronautics, Inc.: Reston, Virginia, 2011. 
2. Nonami, K.; Kendoul, F.; Suzuki, S.; Wang, W.; Nakazawa, D. Autonomous Flying Robots, Unmanned Aerial Vehicles and Micro Aerial Vehicles; Springer: London, UK, 2010.

3. Valavanis, K.P.; Vachtsevanos, G.J. Handbook of Unmanned Aerial Vehicles; Springer: Dordrecht, The Netherlands, 2015.

4. Isk, arani, M.; Givigi, S.N.; Fusina, G.; Beaulieu, A. Unmanned Aerial Vehicle formation flying using Linear Model Predictive Control. In Proceedings of the 2014 IEEE International Systems Conference Proceedings, San Diego, CA, USA, 5-8 October 2014; pp. 18-23.

5. Cummings, M.L.; How, J.P.; Whitten, A.; Toupet, O. The Impact of Human-Automation Collaboration in Decentralized Multiple Unmanned Vehicle Control. Proc. IEEE 2012, 100, 142-149. [CrossRef]

6. Khan, A.; Rinner, B.; Cavallaro, A. Multiscale observation of multiple moving targets using Micro Aerial Vehicles. In Proceedings of the International Conference on Intelligent Robots and Systems (IROS) IEEE/RSJ, Hamburg, Germany, 28 September3 October 2015; pp. 4642-4649.

7. How, J.P.; Fraser, C.; Kulling, K.C.; Ertuccelli, L.F. Increasing autonomy of UAVs. IEEE Robot. Autom. 2009, 16, 43-41. [CrossRef]

8. Goddemeier, N.; Kai, D.; Wietfeld, C. Role-Based Connectivity Management with Realistic Air-to-Ground Channels for Cooperative UAVs. IEEE J. Sel. Areas Commun. 2012, 3, 951-963. [CrossRef]

9. Zeng, Y.; Zhang, R.; Lim, T.J. Wireless communications with unmanned aerial vehicles: Opportunities and challenges. IEEE Commun. Mag. 2016, 54, 36-42. [CrossRef]

10. Zhou, Y.; Cheng, N.; Lu, N.; Shen, X.S.J. Multi-UAV-Aided Networks: Aerial-Ground Cooperative Vehicular Networking Architecture. IEEE Veh. Technol. Mag. 2015, 10, 36-44. [CrossRef]

11. Rady, S.; Kandil, A.A.; Badreddin, E. A hybrid localization approach for UAV in GPS denied areas. In Proceedings of the IEEE/SICE International Symposium on System Integration (SII), Kyoto, Japan, 20-22 December 2011; pp. $1269-1274$.

12. Romaniuk, S.; Ambroziak, L.; Gosiewski, Z.; Isto, P. Real Time Localization System with Extended Kalman Filter for Indoor Applications. In Proceedings of the 21th International Conference on Methods and Models in Automation and Robotics (MMAR), Miedzyzdroje, Poland, 29 August-1 September 2016; pp. 42-47.

13. Zhou, M.; Prasad, J.V.R. Transient characteristics of a fuel cell powered UAV propulsion system. In Proceedings of the International Conference on Unmanned Aircraft Systems (ICUAS), Atlanta, GA, USA, 28-31 May 2013; pp. 114-123.

14. Shiau, J.K.; Ma, D.M.; Yang, P.Y.; Wang, G.F.; Gong, J.H. Design of a Solar Power Management System for an Experimental UAV. IEEE Trans. Aerosp. Electron. Syst. 2009, 45, 1350-1360. [CrossRef]

15. Kondratiuk, M.; Ambroziak, L. Concept of the Magnetic Launcher for Medium Class Unmanned Aerial Vehicles Designed on the Basis of Numerical Calculations. IEEE J. Theor. Appl. Mech. 2016, 54, 163-177. [CrossRef]

16. Reck, B. First design study of an electrical catapult for unmanned air vehicles in the several hundred kilogram range. IEEE Trans. Magn. 2003, 39, 310-313. [CrossRef]

17. Guruge, P.; Kocer, B.B.; Kaycan, E. A novel automatic UAV launcher design by using Bluetooth low energy integrated electromagnetic releasing system. In Proceedings of the Humanitarian Technology Conference (R10-HTC), Waterfront Hotel Cebu, Philippines, 9-12 December 2015; pp. 1-4.

18. Schmitt, F.; Schulte, A. Mixed-Initiative Mission Planning Using Planning Strategy Models in Military Manned-Unmanned Teaming Missions. In Proceedings of the IEEE International Conference on Systems, Man, and Cybernetics (SMC), Hong Kong, 9-12 October 2015; pp. 1391-1396.

19. Olson, L.; Burns, L. A common architecture prototype for army tactical and FCS UAVS. In Proceedings of the 24th Digital Avionics Systems Conference, Washington, DC, USA, 30 October-3 November 2005; pp. 8B5.1-8B5.11.

20. Giachetti, R.; Wangert, S.; Eldred, R. Interoperability Analysis Method for Mission-Oriented System of Systems Engineering. In Proceedings of the IEEE International Systems Conference (SysCon), Orlando, USA, 8-11 April 2019; pp. 1-6.

21. Fahlstrom, P.; Gleason, T. Introduction to UAV Systems, 4th ed.; Wiley, Chichester, United Kingdom, 2012.

22. Mystkowski, A. Implementation and investigation of a robust control algorithm for an unmanned micro-aerial vehicles. Robot. Auton. Syst. 2014, 62, 1187-1196. [CrossRef]

23. Kownacki, C. Design of an adaptive Kalman filter to eliminate measurement faults of a laser rangefinder used in the UAV system. Aerosp. Sci. Technol. 2015, 41, 81-89. [CrossRef]

24. Zhiteckii, L.S.; Pilchevsky, A.Y.; Kravchenko, A.O.; Bykov, B.V. Modern control theory for designing lateral autopilot systems of UAV. In Proceedings of the IEEE International Conference on Actual Problems of Unmanned Aerial Vehicles Developments (APUAVD), Kyiv, UKraine , 13-15 October 2015; pp. 160-164.

25. Guerrero, J.A.; Lozano, R. Flight Formation Control; Wiley-ISTE: Hoboken, NJ, USA, 2012.

26. Rabbath, C.A.; Lechevin, N. Safety and Reliability in Cooperating Unmanned Aerial Systems; World Scientific Publishing Company: Singapore, 2010.

27. Gosiewski, Z.; Ambroziak, L. Formation Flight Control Scheme for Unmanned Aerial Vehicles. Lect. Notes Control Inf. Sci. 2012, $422,331-340$.

28. Kownacki, C.; Ambroziak, L. Flight control of a formation of fixed-wing UAVs based on the idea of flexible structure. In Proceedings of the 12th International Conference Mechatronic Systems and Materials MSM 2016-Intelligent Technical Systems, Bialystok, Poland, 3-8 July 2016.

29. Giulietti, F.; Innocenti, M.; Innocenti, M.; Pollini, L. Dynamic and control issues of formation flight. Aerosp. Sci. Technol. 2005, 9 , 65-71. [CrossRef] 
30. Giulietti, F.; Pollini, L.; Innocenti, M. Autonomous Formation Flight. IEEE Control Syst. Mag. 2000, 20, 34-44.

31. Johnson, E.N.; Calise, A.J.; Sattigeri, R.; Watanable, Y.; Madyastha, V. Approaches to vision-based formation control. In Proceedings of the 43rd IEEE Conference on Decision and Control CDC, Paradise Island, The Bahamas, 14-17 December 2004; pp. 1643-1648.

32. Lin, F.; Peng, K.; Dong, X.; Zhao, S.; Chen, B.M. Vision-based Formation for UAVs. In Proceedings of the 11th IEEE International Conference on Control \& Automation (ICCA), Taichung, Taiwan, 18-20 June 2014; pp. 1375-1380.

33. Dehghani, M.A.; Menhaj, M.B. Integral sliding mode formation control of fixed-wing unmanned aircraft using seeker as a relative measurement system. Aerosp. Sci. Technol. 2016, 48, 318-327. [CrossRef]

34. Lvlong, H.; Peng, B.; Xiaolong, L.; Jiaqiang, Z.; Weijia, W. Feedback formation control of UAV swarm with multiple implicit leaders. Aerosp. Sci. Technol. 2018, 72, 327-334.

35. Jianhua, W.; Liang, H.; Xiwang, D.; Qingdong, Li, Zhang, R. Distributed sliding mode control for time-varying formation tracking of multi-UAV system with a dynamic leader. Aerosp. Sci. Technol. 2021, 111, 106549.

36. Li, N.H.M.; Liu, H.H.T. Formation UAV flight control using virtual structure and motion synchronization. In Proceedings of the American Control Conference, Seattle, WA, USA, 11-13 June 2008; pp. 1782-1787.

37. Kownacki, C.; Ołdziej, D. Fixed-wing UAVs Flock Control through Cohesion and Repulsion Behaviors Combined with a Leadership. Int. J. Adv. Robot. Syst. 2016, 13, 36. [CrossRef]

38. Muslimov, T.R.; Munasypov, R.A. DConsensus-based cooperative control of parallel fixed-wing UAV formations via adaptive backstepping. Aerosp. Sci. Technol. 2021, 109, 106416. [CrossRef]

39. Ziquan, Y.; Youmin, Z.; Bin, J.; Xiang, Y.; Jun, F.; Ying, J.;Tianyou, C. Distributed adaptive fault-tolerant close formation flight control of multiple trailing fixed-wing UAVs. ISA Trans. 2020, 106, 181-199.

40. Hao, L.; Qingyao, M.; Fachun, P.; Frank, L.L. Heterogeneous formation control of multiple UAVs with limited-input leader via reinforcement learning. Neurocomputing 2020, 412, 63-71.

41. Buzogany, L.E.; Pachter, M.; D'azzo, J.J. Automated control of aircraft in formation flight. In Proceedings of the AIAA Guidance, Navigation and Control Conference, 1993; pp. 1349-1370.

42. Hall, J.K.; Pachter, M. Formation maneuvers in three dimensions. In Proceedings of the 39th IEEE Conference on Decision and Control, Sydney, NSW, Australia, 12-15 December 2000; pp. 364-369.

43. Pachter, M.; D'azzo, J.; Dargan, J.L. Automatic formation flight control. J. Guid. Control. Dyn. 19940, 17, 1380-1383. [CrossRef]

44. Cheng, Z.; Necsulescu, D.S.; Kim, B.; Sasiadek, J.Z. Nonlinear Control for UAV Formation Flying. In Proceedings of the 17th World Congress The International Federation of Automatic Control, Seoul, Korea, 6-11 July 2008; pp. 791-796.

45. Kim, D.M.; Nam, S.; Suk, J. A modified nonlinear guidance logic for a leader-follower formation flight of two UAVs. In Proceedings of the ICCAS-SICE Conference, Fukuoka City, Japan, 18-21 August 2009; pp. 5734-5739.

46. Ambroziak, L.; Gosiewski, Z. Two stage switching control for autonomous formation flight of unmanned aerial vehicles. Aerosp. Sci. Technol. 2015, 46, 221-226. [CrossRef]

47. McCammish, S.; Pachter, M.; D'azzo, J.J.; Reyna, V. Optimal Formation Flight Control. In Proceedings of the AIAA Guidance, Navigation and Control Conference, San Diego,CA, USA, 29-31 July 1996.

48. Du, M.; Yamashita, Y. Optimal Control of Formation Flight Based on MLD Systems. In Proceedings of the IEEE International Conference on Control Applications, Singapore, 1-3 October 2007; pp. 904-909.

49. Boskowic, J.D.; Sun, Z.; Song, Y.D. An adaptive reconfigurable formation flight control design. In Proceedings of the 2003 American Control Conference, Denver, CO, USA, 4-6 June 2003; pp. $284-289$.

50. Schumacher, C.J.; Kumar, R.. Adaptive control of UAVs in close-coupled formation flight. In Proceedings of the American Control Conference, Denver, CO, USA, 4-6 June 2003; pp. 849-853.

51. Shin, J.; Kim, H.J. Nonlinear Model Predictive Formation Flight. IEEE Trans. Syst. Man Cybern. Part A Syst. Humans 2009, 39, 1116-1125. [CrossRef]

52. Li, B.; Liao, X.H.; Sun, Z.; Li, Y.; Song, Y.D. Robust Autopilot for Close Formation Flight of Multi-UAVs. In Proceedings of the 2006 Thirty-Eighth Southeastern Symposium on System Theory, Cookeville, TN, USA, 5-7 March 2006; pp. $258-262$.

53. Raffard, R.L.; Tomlin, C.J.; Boyd, S.P. Distributed optimization for cooperative agents: Application to formation flight. In Proceedings of the 43rd IEEE Conference on Decision and Control CDC, Paradise Island, Bahamas, 14-17 December 2004; pp. 2453-2459.

54. Kuwata, Y.; How, J.P. Cooperative Distributed Robust Trajectory Optimization Using Receding Horizon MILP. IEEE Trans. Control Syst. Technol. 2011, 19, 423-431. [CrossRef]

55. Radmanesh, M.; Kumar, M. Flight formation of UAVs in presence of moving obstacles using fast-dynamic mixed integer linear programming. Aerosp. Sci. Technol. 2016, 50, 149-160. [CrossRef]

56. Chen, Y.; Yu, J.; Su, X.; Luo, G. Path Planning for Multi-UAV Formation. J. Intell. Robot. Syst. 2015, 77, 229-246. [CrossRef]

57. Suzuki, M.; Uchiyama, K.; Bennet, D.; Macinnes, C. Three-Dimensional Formation Flying Using Bifurcating Potential Fields. In Proceedings of the AIAA Guidance, Navigation, and Control Conference, Toronto, ON, Canada, 8-11 August 2009; pp. 1-11.

58. Nagao, Y.; Uchiyama, K. Formation Flight of Fixed- Wing UAVS Using Artificial Potential Field. In Proceedings of the 29th Congress of the International Council of the Aeronautical Sciences, St. Petersburg, Russia, 7-12 September 2014; pp. 1-8.

59. Kokume, M.; Uchiyama, K. Guidance Law Based on Bifurcating Velocity Field for Formation Flight. In Proceedings of the AIAA Guidance, Navigation, and Control Conference, Guidance, Navigation, Toronto, ON, Canada, 2-5 August 2010; pp. 1-10. 
60. Paul, T.; Krogstad, T.R.; Gravdhal, J.T. Modelling of UAV Flight Using 3D potential Field. Simul. Model. Pract. Theory 2008, 16, 1453-1462. [CrossRef]

61. Tahk, M.J.; Park, C.S.; Ryoo, C.K. Line-of-sight guidance laws for formation flight. J. Guid. Control. Dyn. 2005, 28, 708-716. [CrossRef]

62. Betser, A.; Vela, P.A.; Pryor, G. Tannenbaum, Flying in formation using a pursuit guidance algorithm. In Proceedings of the American Control Conference, Portland, OR, USA, 8-10 June 2005; pp. 5085-5090.

63. Available online: www.topmodelcz.cz (accessed on 20 April 2021).

64. Beard, R.W.; McLain, T.W. Small Unmanned Aircraft, Theory and Practice; Princeton University Press: Princeton, NJ, USA, 2012.

65. Roskam, J. Airplane Flight Dynamics and Automatic Flight Controls, Parts I E II; DAR Corporation: Lawrence, KS, USA, 2012.

66. Stevens, B.L.; Lewis, F.L. Aircraft Control and Simulation, 2nd ed.; John Wiley \& Sons: Hoboken, NJ, USA, 2003.

67. Available online: https://www.darcorp.com/advanced-aircraft-analysis-software/ (accessed on 20 April 2012).

68. Available online: http:/ / tornado.redhammer.se (accessed on 20 April 2012).

69. Ambroziak, L.; Gosiewski, Z.; Kondratiuk, M. Aerodynamics Characteristics Identification of Micro Air Vehicle. Trans. Inst. Aviat. 2011, 216, 17-29. (In Polish)

70. Nise, N.S. Control Systems Engineering, 8th ed.; John Wiley \& Sons: Hoboken, NJ, USA, 2019.

71. Rauw, M. FDC 1.2-A Simulink Toolbox for Flight Dynamics and Control Analysis, 2nd ed.; 2001. Available online: https: / / www.semanticscholar.org/paper/FDC-1.2-A-Simulink-Toolbox-for-Flight-Dynamics-and-Rauw / dfbc4526f57f83e97c030b5 27fd0b6dfc2afdeaf (accessed on 30 June 2021).

72. Available online: https:/ / www.mathworks.com/help/aeroblks/ (accessed on 20 April 2012).

73. Available online: https://www.micropilot.com/ (accessed on 20 April 2012).

74. Available online: https://www.lockheedmartin.com/content/dam/lockheed-martin/rms/photo/procerus/Kestrel-FlightSystems-brochure.pdf. (accessed on 20 April 2012).

75. Rankin, J. GPS and differential GPS: An error model for sensor simulation. In Proceedings of the Position, Location and Navigation Symposium, Las Vegas, NV, USA, 10-15 April 1994; pp. 260-266.

76. Khatib, O. Real-time obstacle avoidance for manipulators and mobile robots. Int. J. Robot. Res. 1986, 17 , 90-98. [CrossRef]

77. AL-Sultan, K.; Aliyu, M. A new potential field-based algorithm for path planning. J. Intell. Robot. Syst. 1996, 17, 265-282. [CrossRef]

78. Xiao, B.; Yu, L.; Li, S.; Chen, R. Research of escaping local minima strategy for artificial potential field. J. Syst. Simul. 2007, 19, 4495-4503.

79. Montiel, O.; Orozco-Rosas, U.; Sepulvda, R. Path planning for mobile robots using Bacterial Potential Field for avoiding static and dynamic obstacles. Expert Syst. Appl. 2015, 42, 5177-5191. [CrossRef]

80. Langelaan, J.W.; Alley, N.; Neidhoefer, J. Wind field estimation for small unmanned aerial vehicles. J. Guid. Control. Dyn. 2011, 34, 1016-1030. [CrossRef] 